$$
\text { ULCIN) ULCHN }
$$

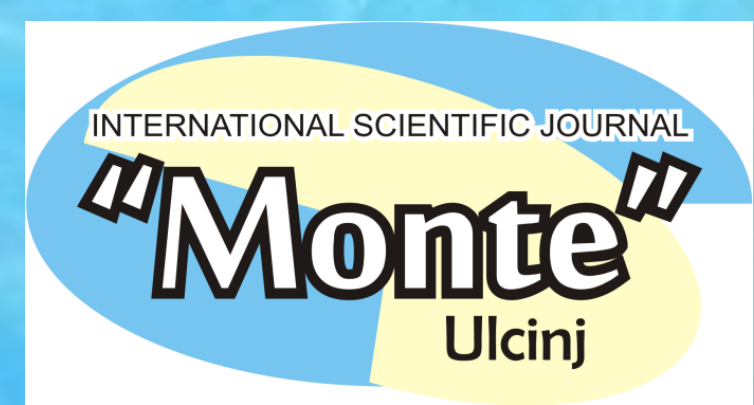

ISSJM (Ulcinj. Online) ISSN 2661-2666

\title{
International Scientific Journal Monte (ISJM)
}

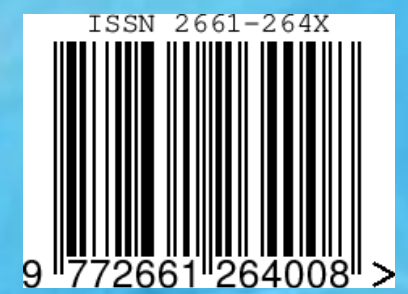

Volume 3, Issue (No.) 1 (2020): April 


\section{Newsroom}

Prof.Dr. Diana Shehu (Albania)

Prof. Dr. Akhter Alam (India)

Prof. Dr. Sonja Vitanova (Macedonia)

Prof. Dr. Tibor Petres (Hungary)

Prof. Dr. Michael Minch (USA)

\section{Editor of the Scientific Magazine}

Prof. Dr. Elez Osmanovic (Montenegro) - Faculty of Economics, University of Shkodra "Luigj Gurakuqi”, Albania

Prof. Dr. Alba Dumi (Albania) - Dean of Tirana Business University (TBU), University of Tirana, Albania

Publishing house:

Institute for Scientific Research and Development-Montenegro 


\section{Scientific Board}

- Prof. Dr. Konstantin Pochivalov, (Russia)

- Prof. Dr. Nevenka Žarkić-Joksimović, (Serbia)

- Prof. Dr. Slađana Benković FON (Serbia)

- Prof. Dr. Dragoljub Jankovic (Montenegro)

- Prof. Dr. Anatoly Avdenko (Ukraina)

- Prof. Dr. Valentin Nedeff (Romania)

- Prof. Dr. Constantin Bungau (Romania)

- Prof. Dr. Vladimir P. Sergienko (Belorus)

- Prof. Dr. Predrag Dašić (USA)

- Prof. Dr. Hidajet Shehu (Albania)

- Prof. Dr. Laszlo Karpati (Hungary)

- Prof. Dr. Akhter Alham (India)

- Prof. Dr. Brilanda Bushati (Albania)

- Prof. Dr. Seadin Xhaferi (Macedonia)

- Prof. Dr. Astrit Mehmeti (USA)

- Prof. Dr. Kerstin Bree Carlson (Danska)

- Prof. Dr. Robert Dimitrejvski (Macedonia)

- Prof. Dr. Michael Minch (USA)

- Prof. Dr. Muharem Karamujić (Bosnia and Herzegovina)

- Prof. Dr. Arben Malaj (Albania)

- Prof. Asc. Dr. Blerta Dragusha (Albania)

- Prof. Dr. Niké Wentholt (Netherland)

- Prof. Dr. Drita Kruja (Albania)

- Prof. Dr. Laszlo Karpati (Hungary)

- Prof. Dr. Miodrag Brzaković (Serbia)

- Prof. Asc. Dr. Darko Lacmanović (MNE)

- Prof. Dr. Salvator Bushati (Albania)

- Prof. Dr. Sofronija Miladinoski (Macedonia)

- Prof. Dr. Daniel Dobrev, (Bulgaria)

- Prof. Dr. Sampurna Mehta (India)

- Prof. Dr. Heinrich Meister (Switzerland)

- Prof. Dr. Jusuf Mustafai (Macedonia)

- Prof. Dr. Radovan Stojanović (MNE)

- Prof. Dr. Biljana Ciglovska (Macedonia)

- Prof. Dr. Artan Nimani (Kosovo) 
- ANASTAZIJA TANJA ĐELIĆ

THE CONCEPT OF LOCAL ECONOMIC DEVELOPMENT AND TOURISM IN THE EUROPEAN INTEGRATION PROJECT...

- ANTONELLO FIGETTO

- ALBA DUMI

TOURIST ENTERPRISES, CONCEPT ON TOURISM DEVELOPMENT AND ITS ACCOUNTING

- BRIKENA TOLLI

COST METHOD EFFECTIVENESS ANALYSES CASE STUDY - FIXED TELECOMMUNICATION IN ALBANIA

- FRANKO BAGNIOLINI

OPERATING BUDGETS AND THE TOURISTIC TRAFFIC PATTERNS AND THEIR IMPORTANCE.THE GOVERNMENT AND OTHER STAKEHOLDERS OF TOURISM.THEORETICAL TREATMENT ANALYSIS

- MARIO ÇURÇIJA

- EMIRJETA BEJLERI

AN INVESTIGATION OVER POPULATION INCREASE IN URBAN AREAS AND EMPLOYMENT PROSPECTS IN ALBANIA

- $\quad$ SLOBODAN NEŠKOVIĆ

TOURISM INDUSTRY OF THE WESTERN BALKAN COUNTRIES BETWEEN EXISTING RESOURCES AND REGULATION OF THE EUROPEAN UNION

- THERANDA BEQIRI

- ARBËRORA HAXHIJA

IMPACT OF EU GRANTS ON EDUCATION IN KOSOVO .56 


\title{
THE CONCEPT OF LOCAL ECONOMIC DEVELOPMENT AND TOURISM IN THE EUROPEAN INTEGRATION PROJECT
}

\author{
Prof. Assoc. Dr. Anastazija Tanja Đelić \\ Faculty of Law, Security and Protection "Konstantin Veliki" of Niš \\ Union Nikola Tesla University Belgrade, Serbia
}

\begin{abstract}
The aim of our research is to scientifically consider the concept of local economic development and tourism in the project of European integration as important segments of the overall progress of countries. The presented results, recommendations and defined conclusions will benefit the competent entities in the process of improving the state of local administration, tourism economy and integration into the European Union. Also, to other academic workers in further research on current topics. The economic development of local communities is based on the reorganization of business according to the principles of the new public management aimed at the real needs of the population. Tourist resources can be essential postulates of prosperity in all countries, including the Republic of Serbia. The starting hypothesis is that the concept of local economic development and tourism are important areas in the European integration project. At the same time, they mark areas with favorable opportunities for positive trends in society. By applying appropriate methodological procedures of analysis of available contents, synthesis and comparison, we will look at the first-class elements of our topic. The basis of the study is the available materials related to the functioning of local governments and tourism with realistic indicators in various domains of public life. The institutions of the European Union have conceived specific legal legislation in the given areas, as special regulations that are binding for members and countries in certain phases of accession. Our article deals with the improvement of local self-government through the implementation of proven modalities of economic development, where the application of modern management and reforms result in the improvement of the situation at the local level. Public administration needs to learn how to cooperate with local governments in order to gain more support in term of infrastructure investments while gaining more independence in the management of taxes from local touristic activities. Some of the common messages embedded in the abovementioned documents are very important for developing the approach and strategic foundation for sustainable tourism in Republic of Serbia. As it was stated sustainable tourism is positive approach intended to reduce the tensions and frictions created by the complex interactions between the tourism industry, visitors, the environment and the communities which are host to holidaymakers ...i.e., it is an approach which involves working for the long- term viability and quality of both natural and human resources. It can be concluded that the successful economic development of local administrations is ensured by applying modern paradigms of public management modeled on the systems of developed countries. Adequately profiled, tourism can be an essential area of the economy in the European integration project. Despite the obvious shortcomings, Serbia has certain comparative advantages and numerous resources important for its expansion. Geographical position, traffic infrastructure, natural resources, cultural heritage and other benefits indicate real possibilities for accelerated prosperity and successful entry into the community of developed countries. We are of the opinion that the leading state entities must eliminate the obvious weaknesses in the work of local administrations and incorporate the legal legislation of the European Union into their own legislation. It is necessary for the state leaders to pay more attention to the planned investments in tourism, hotel industry and processing industry. Implement the funds of the pre-accession funds of the European Union in fruitful development projects at the local level. Use the favorable strategic position with various natural resources and a healthy environment to promote the tourist economy with accompanying facilities. It is necessary to favor paradigms that motivate foreign investors, where business strategies are formulated based on established international principles. Implement current initiatives in cross-border cooperation projects of local communities and regions in accordance with the proclaimed national interests.
\end{abstract}

Key words: local economic development, tourism, resources, Serbia, European Union 


\section{INTRODUCTION}

The local economic development depends on the integration of the tourism sector with the whole economy. Tourism is forecast to double in size by 2030 as one of the fastest growing economies in the world - Serbia included. It is a key economic driver at national, state, territory and local levels throughout our country and the outlook is very promising.

From a strictly economic standpoint, "tourism is the second most important global sector, after financial services, and one of the fastest growing service industries for many economies in the world". (Alberti \& Giusti, 2012, p. 264) In line with this observation, Rogerson points out that "tourism is an evolving and dynamic activity that is easily adapted to social, political and economic changes. Its impact on the development of countries is evident, and that is why it has become one of the pillars of the world economy". (Rogerson, 2012, p. 154) To ratify these considerations, the World Tourism Organization (UNWTO), one of the main reference institutions in the sector, considers that the leisure industry represents, roughly, $10 \%$ of the gross world product; and, at the labor level, $9.6 \%$ of all jobs created.

Tourism activity is an important driver of the global economy, ensuring monetary circulation, through tourism receipts, to other economic circuits. By developing tourism activities, countries can increase their national production, with a positive effect on their Gross Domestic Product (GDP). Tourism services and cultural products should be promoted together in development efforts, as generators for regional progress in areas with partially valued heritage potential.

A strategic and integrated approach of sustainable cultural heritage tourism development must include all types of externalities, both positive and negative, and should be included in local policies for development as a priority, offering economically driven opportunities. Intensive development of tourism, which contributes to an increased added value, must be implemented in services through technology. Cultural heritage, promoted through tourism, creates jobs, drives innovation, supports public services development and local entrepreneurship (including transport and communication infrastructures), generates prosperity, and encourages participation of citizens.

Tourism is one of the world's largest and most dynamic forms of social and cultural exchange. It is also one of the largest forms of economic activity and a driver of economic development. While international visitor arrivals are predicted by the UN World Tourism Organization to reach 1,000 million within the next few years, domestic tourism is estimated to be more than five times that amount. Their research demonstrates that interest in the environment, culture and heritage is a primary motivation for more than $50 \%$ of travel, and is a consistently growing market area.

The contribution that tourism can make to poverty alleviation, to conservation of the natural and cultural heritage, and to overall sustainable development can be substantial. This is especially so in developing countries like Serbia, where natural resources and landscapes are still relatively untouched and where few other activities have a sustainable development potential, from an economic or environmental perspective. Furthermore, tourism has proved to be in many countries a much more sustainable development option that intensive agriculture, forestry, extractive mining or other primary activities.

Tourism has a major impact on local communities in tourist destinations. It can be a significant source of income and employment for local people. It can also pose a threat to the social fabric of an area and its natural and cultural heritage, which it depends on, but if it is well planned and managed it can be a force for their conservation. These stakes have led to a recognition of the tourism sectors need to incorporate the principles of sustainable development contained in Agenda 21, which was adopted at the Earth Summit in 1992.

The development of tourism in local communities is often an illustration of a community taking advantage of resources within community, which is an example of self-help approach to local economic development. The most prevalent approaches are: the self-help approaches to community development which is a strategy of community development in tourism development. The technical assistance approach to community development is based on technical information and expertise for improving the tourism in local communities. However, this approach has a downside and it can limit community capacity building. This is because governments use the technical approach to develop tourism and this can disempower local community and create dependency. (Begovic, Vacic, Matković \& Mijatović, 2016, p. 14) 
Some writers referred to technical assistance as a key element in building community capacity and increase skill (Rural Voices for Conservation Coalition, 2007). According to Pike, Rodriguez and Tomanev, the support of the government through a technical assistance can limit building capacity. Yet at the same time, government can also develop partnerships that foster community capacity building for tourism development. Thus, in third world countries particularly, without the government support, community capacity cannot be achieved.

The conflict approach stresses the equal distribution of resource in community and usually focuses on those with limited power. The idea of the conflict approach is to get people together to change a community. In this study, this approach has referred to decentralization in tourism organization and so it can refer to community participation in tourism development. In summary, community development literature is relevant to this study as it provides the rational and theoretical background for tourism development.

\section{MATERIALS AND METHODS}

Local economic development is a process of change in which the public and private sectors jointly recognize common problems in the economic environment, implement a policy and development plan that affect the reduction of problems and make the local community more competitive and the economy more powerful, thus improving the standard of living in the local community. Competitiveness is the most common driver of change. However, low entrepreneurial potential of local authorities and lack of financial resources are the most common obstacle. (Vasilijevic, 2012, p. 65)

Modern tendencies in local communities are that entrepreneurial management and activities of local authorities rely heavily on these partnerships, which appear in different areas of service delivery through the implementation of various arrangements and development projects. In the area of public service delivery, local authorities are given the opportunity to stimulate local initiative, increase local potential, attract investments and stimulate employment growth in their territory, and thus local economic development.

Local government is an important segment of the public sector when it comes to supporting economic development. Citizens expect local authorities to make efforts to tackle unemployment and raise quality of life. Economic development of local communities must be a priority, both for local government and central government. The most important goal, which proclaims the concept of local economic development, is to increase the number of employees in the territory of the local self-government unit. It can also be defined as an increase in the capacity of the local economy to create wealth for local residents, and therefore to improve their standard of living through increased employment, real wages, value of citizens' assets, etc.

Local economic development requires the development of new public management. It relies not only on the capacity of executive and governing bodies of government, but also on the partnership and close cooperation of organizations, institutions and individuals who contribute to the realization of public interests. There is probably no part of public administration that plays a more significant role in achieving "bono publico" as much as local economic development in practical application.

In the narrow sense, local economic development is understood as a strategic planning process through the partnership of local authorities, the private and non-governmental sectors, which, by focusing on stimulating investments, will ensure high and stable economic growth of local community. Each local economic development strategy is conceptualized based on the comparative advantages of the local community in relation to existing or potential markets. An additional objective of local economic development is to strengthen competitiveness, which in turn ensures sustainable development. There are two strategies for encouraging local development:

1. Attracting foreign firms to invest in the local community, through incentives given by local authorities to firms such as tax breaks and cheap land;

2. Encouragement of local groups by local authorities to develop their own businesses and thereby accelerate the economic development of the local community.

However, local economic development is not just about economic development seen in local contexts, as is often mistaken. The essence of local economic development lies in the collaboration of key local actors, partnerships with senior management, as well as a clear intention to effectively take advantage of the comparative advantages 
of a particular local community: economic and entrepreneurial potential, workforce structure, infrastructure network, geographical location and cultural historical specifics. It examines whether what benefits a country's entire economy can be applied for development purposes in a particular local community.

The concept of local economic development introduces competition, which is a starting point in economic reforms, from the macroeconomic level to the level of relations between the various political and territorial units that make up the state. (Neskovic, S., Djelic, T. A., Antonovic, R., Lutovac, M. \& Ketin, S., 2020, p. 4063)

Central government is an "indispensable" factor in stimulating local economic development, hence the partnership between local and republic authorities is often referred to as the "model of local development state". (Begovic, Vacic, Matković \& Mijatović, 2016, p. 75) The state adopts legislation, develops an organizational support network and establishes general development guidelines, which in contemporary economy is considered a precondition for the functioning of entrepreneurial administration.

The reform processes that changed the essence of the modern state in the late 1990s introduced a new concept of doing business into the socio-economic environment. These processes strongly affect local communities as important economic-political and service centers. By implementing comprehensive reforms of the welfare state, introducing modern governance, developing entrepreneurship, local government is taking an active role in stimulating local economic development, attracting foreign and domestic capital, increasing staffing and implementing public-private partnerships, with a perspective to solving problems and providing quality services to citizens and business.

The importance of entrepreneurial engagement of local authorities and the active participation of higher levels of government has been implanted into the practice of many local governments in the developed world, including Republic of Serbia. Implementation of business incubators, industrial and technological parks, free zones and various forms of public-private partnership are some of the elements of an entrepreneurial approach. An important segment is represented by the various forms of tax incentives and benefits provided by the local government or higher levels to the economy, as well as other projects by which the state provides funds to the local government to create an attractive environment for investors.

Local communities and central governments have developed a new partnership, which has led to an increase in the overall quality and scope of public services. Local authorities that have embraced the principles of entrepreneurial administration, investing their resources in modernizing management, professionalizing employed personnel, applying modern development methods, are becoming more efficient and competitive in providing services of adequate scope, high standard and quality, in short providing services that are tailored to the needs of citizens and business.

In market conditions, entrepreneurial local government should be most focused on attracting capital as a highly mobile resource. Capital easily moves from one local community to one that offers the most favorable conditions for business and profit making. That is why there is fierce competition between local authorities in attracting capital, but also other factors of production. Successful attraction of these factors enables the realization of the economic development strategy, that is, the establishment of sustainable economic development.

The key factor of entrepreneurship is innovation. With this in mind, the success of local governments in entrepreneurship is reflected in innovation in attracting investment. Entrepreneurial activity of the local government, within the framework of the local economic development strategy, is aimed at communication with investors, particularly owners of all factors of production. In addition, local authorities should develop and implement an effective public relations (PR) strategy to inform potential investors about the benefits of coming to their community. One of the crucial components is the creation and up-to-date maintenance of the website, with important local information available. In presenting the local community to the public, and especially to the target group of relevant individuals and businesses, entrepreneurship and innovation form an important segment of the “entrepreneurial spirit” of local government. (Begovic, Vacic, Matković \& Mijatović, 2016, p. 62)

The most important instruments of local economic development include public-private partnerships and concessions, business incubator centers, industrial, technology and science parks, various financial aid programs and funds, business and free zones, brownfield and greenfield investments. As an instrument of local economic development of particular importance, we should also mention the Local Economic Development Offices, which promote economic development in the local community in a professional and systematic way. Local governments 
most often recognize the need to strengthen their economic base when the problem of unemployment is intensified. At that point, usually the first line of thought is to do everything possible to attract a large investor or strategic partner. In this way, local economic development in Serbia has begun to boil down to a group of instruments whose main purpose is to attract foreign investors. It is often considered that if a municipality is "fortunate" with attracting one or two large investors, it has solved its biggest problems for the next ten or twenty years.

To address these issues facing local communities in our country, comprehensive cooperation and partnership between the local community, private and civilian sectors is necessary. In other words, not only local governments have an essential role in local economic development, but economic development is stimulated through active participation with other entities such as private companies, non-governmental organizations, central authorities, citizen advisory bodies and various foundations and financial institutions. The pragmatic benefit of local economic development is that through modern business ventures it is possible to increase employment and increase fiscal benefits. The basic meaning of local economic development is reflected in the effort to improve the quality of life in a particular local community.

\section{RESULTS}

Since the tourism industry operates in a global scale, the role of local public administration becomes more evident to be enough aggressive and aware of what they have to do in order to make their communities more and more involved in it and its revenues managed and invested in their local economies. They must learn how to match better local needs, demands and resources with global interest in local areas and communities.

At the same time, it is their responsibility to set up a stable infrastructure which in touristic terms is evidenced by public services offered, which benefit not only to local communities but at the same time support and in many cases reinforce the decision to tour of different tour operators and tourists. We can evidence more and more common initiatives of local governments involved in development projects and in partnerships with organizations operating in a global scale by helping local administration to gain competences necessary for the successful operation in supporting and managing the tourism sector.

Local economic development has become a global phenomenon. As we mention in previous chapter, this concept involves different activities, factors and participants and there is not a definition which may help to understand in synthesis what local economic development is. For the single territory, it is the challenge of enhancing prosperity and well-being. For a nation as a whole, a chance of development on a global scale starts from the local level. (Pedrana, 2013, p. 52)

Local economic development involves different strategies and issues, first of all, the relationship between private and public in the development of a local area. The institutional framework and rules and norms involved are essential for the good governance of local community. On the other hand, the local context and community and the partnership between private and public sector are essential for the development of all aspects and strategies involved.

Another cause of failure of traditional policies is the tendency to replicate standardized policies in different areas without a complete analysis of the local economic, social and institutional context. Moreover, traditional policies usually address to the promotion of specific industrial sectors, whereas local policies may address more to the development of networks and values chain in different sectors. Another aspect connected with local economic development is the territorial competition. Territories compete to attract investments, which may create competitive assets for the local development. Moreover, territories may compete to attract foreign companies in order to invest in the local production.

For the single enterprise, the territory may be considered as a resource, from which it gets inputs and skills for its activity. The area in which an enterprise is located is not just considered the location, but also a place where elements like institutions, social relations, capabilities and culture is deeply integrated.

The first studies on the impacts on territory by tourism were conducted in 1960s. They were about the spaces involved in tourism. For instance, Wilson and Clavé, analyze the relationship between space and tourism, through the difference between three regions, the departure, the transit and the arrival. (Wilson \& Clave, 2013, p. 165) 
Tourism is connected first of all with the accessibility of an area. In order to develop a tourist destination, transport systems and infrastructures help tourists in arriving to a destination. On this point, the role of public institutions and policies is crucial, in order to create the local structures and infrastructures to be accessible. Education and local skills, together with local culture and traditions, are often the element which attracts tourists to a destination. The tourism management has to be educated to receive people as tourists, with adequate skills. After the first tourists, the local industry tissue must be organized and created, in order to receive more tourists. Inward investments are essential for the development of an area.

Three are the main features in a tourism destination. First of all, the complexity of the local system of supply has to be analyzed. There are different enterprises with different purposes, which may not have the same concept of what the tourism destination is and how to improve it. The second important factor to be considered is the relationship with the territory. The main attraction for tourists is the natural environment, together with the social and cultural one. The third characteristic concerns with the seasonality and all economic, social and cultural problems.

The potential of a tourism destination is linked to the territory, especially in community tourism destination. The protection of the local context has to be the priority for the local government and local policies. Therefore, the potential policies of the local context have to be addressed to the sustainability, not only of the local economy, but also to the local natural and socio-cultural environment.

In tourism, the territory becomes the supply of the destination. Therefore, the use of the territory has to be in a sustainable view of the tourism in a destination. There are different effects of tourism on a destination. In figure 4 there are the positive and negative effects of tourism on the destination.

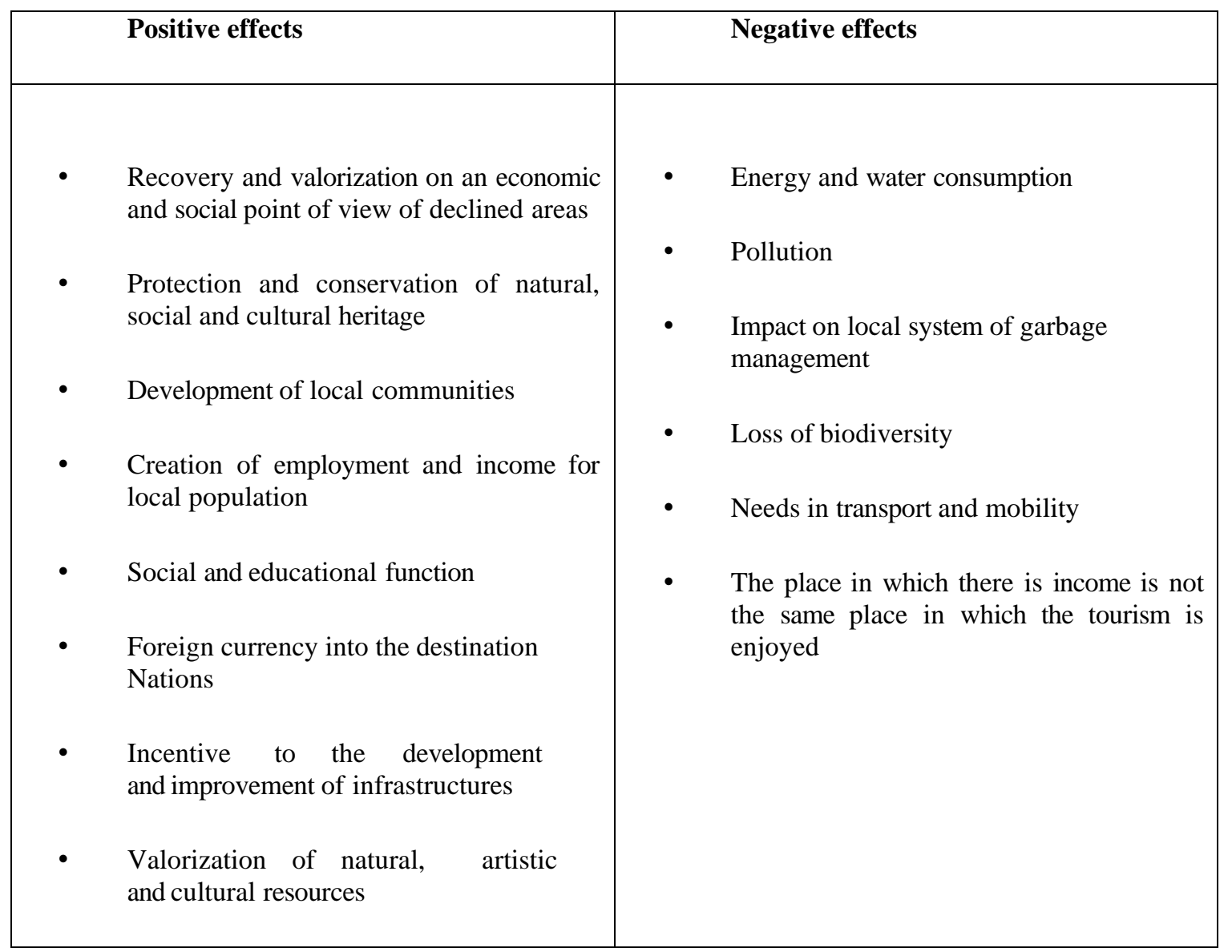

Figure 1. Possible effects of tourism on territory 
Source: Pedrana, M. (2013) Local economic development policies and tourism-An approach to sustainability and culture, Regional Science Inquiry Journal Vol. V, p. 97.

The positive effects are obviously connected with the local economic development of community. The increase in income and employment is the main positive effect of tourism on a defined area. A second important effect concerns the valorization of areas in which there had been industries and where they left from the area. Such areas may have high unemployment and risks connected with the decline of the area. Natural parks may attract tourists and therefore have the money for the protection of the natural resources. (Musaraj, 2016, p. 54)

However, there may be also negative effects. The first one is pollution and the deterioration of the environment. The natural, social and cultural environment may be deteriorated by the use of tourism, especially in the development phase, when mass tourists are coming to tourism destinations.

When we analyze general problems encountered by local human resources for the development of the touristic sector, probably under the influence of the globalization of the industry, they can be defined in similar ways, even if the touristic sector of a community is a consolidated one or if it is in the way to set up its infrastructure. This change in the chain of creation and provision of the touristic service creates from one side the increasing need for capabilities from international operators to deal with small localities features and from the other side the widening of origin countries of tourists makes necessary the immediate enlarge of capabilities of local operators to serve a multicultural client more demanding when it comes to the service standards.

These problems can generally be defined as lack of qualified staff both operational and managerial, failure in setting up and applying strategies of human development in a local level to support tourism development, lack of matching global needs from the touristic sector with the innovative capabilities of these localities.

Tourism studies curricula often create general profiles of operators or managers in the field of tourism as well as in administrating revenues from local touristic taxes. This evidences once again the need to establish a clear definition of the need to acquire capabilities which are a faster answer to the demands of the industry and the long run capacity building for local human resources to support the tourism sector and the area development which find a better solution in professional high schools and universities curricula.

\section{Discussions}

Natural values, cultural heritage and hospitality of people are among major appeals recognized by the strategic documents in Serbia and official statements of policy makers in the field of tourism. For the Government of Serbia, tourism is one of the priority areas in further socioeconomic development and also important for its reform within the process of accession to the EU. At the same time, the progress made towards EU integration during the last years provides important conditions and requirements for tourism development. In 2008,

Republic of Serbia signed the "Stabilization and Association Agreement" and in 2012, its candidate status was approved. Number of foreign tourists is increasing in Serbia, as well as the number of people travelling abroad, owning to the introduction of visa-free travel throughout EU countries for Serbian citizens.

At the national level, there is a Ministry of Trade, Tourism and Telecommunications of Republic of Serbia, and the National Tourism Organization of Serbia, dealing with promotion and market research of tourism, supporting implementation of the Tourism Strategy and tourism development. At the local level, there are municipalities and, in some cases, local tourist organizations, mainly funded by local authorities. The tourism planning and development, including human capacities and infrastructure, is under way mainly at the national level.

Being signatory of numerous global and EU conventions and agreements, Serbia has taken responsibility for their implementation in accordance with sustainability principles embedded in each of the documents. Starting from the globally accepted Millennium Development Goals, through the Convention on Biological Diversity with its Guidelines on Biodiversity and Tourism developed in 2004, Serbian policy and approach in developing sustainable tourism is under unavoidable implications of the broad set of documents, adopted at the national level over. Receiving the status of EU candidate country, Serbia is to comply with principles and directions developed by the EU over the past decade. The European Union Strategy for Sustainable Development (EU SDS), developed 
by the European Council, adopted in 2001 and revised in 2006 and 2009 is an umbrella document. Specific guidelines for the policy development and practice towards sustainability and EU integration are suggested by the most relevant documents for sustainable tourism developed at the European level, such as the Declaration on Ecotourism (2002), Declaration on Climate Change and Tourism (Davos Declaration), as well as the Agenda for a Sustainable and Competitive European Tourism (2007).

Since the Instrument for Pre-accession Assistance (IPA) is one of the main funding mechanisms of the EU for the accession countries, it is important to consider its Strategic Coherence Framework (SCF) document, setting Serbia's economic, social and environmental development goals. It emphasizes the importance of the environment in tourism development in terms of protection of natural values, but also in terms of improving the waste and water management and environmental services crucial for both economic development and societal well-being, and their sustainability.

Implementing the policy and projects in Serbia today and in the future needs a significant support, both technical and financial, to tourism, as well as to other fields of development. Therefore, it is very important to consider the European Principles for the Environment (EPE) as an initiative of the five signatory European-based Multilateral Financing Institutions (MFIs): Council of Europe Development Bank (CEB), European Bank for Reconstruction and Development (EBRD), European Investment Bank (EIB), Nordic Environment Finance Corporation (NEFCO) and Nordic Investment Bank (NIB). It is founded on their commitment to promote and ensure sustainable development and environmental principles, practices and standards associated with financing the projects.

For projects located in the Member States of the EU, the European Economic Area countries, the EU Acceding, Accession, Candidate and potential Candidate Countries, the EU approach, which is defined in the EC Treaty and the relevant secondary legislation is the logical and mandatory reference. The projects in this region should also comply with any obligation and standards upheld in relevant Multilateral Environmental Agreements. Since one of them, the European Bank for Reconstruction and Development (EBRD) is present in Serbia providing funds for projects in different fields, including tourism, it is of particular interest for policy makers and implementers to understand, respect and comply with the principles they incorporate into its Social and Environmental Policyranking the financing of sustainable development projects among the highest priorities. The Bank has defined a set of specific Performance Requirements ("PR's") that clients are expected to meet, covering key areas of environmental and social impacts and issues. Under each of the PR's, there are objectives, scope and specific steps and activities described in order to provide clear guidance for project holders and stakeholders.

The most relevant strategies and legislation in the field of tourism in Serbia have been developed and adopted over the last ten years, supported by foreign technical and financial aid. However, as it was stated, the "plan implementation is still at the low level, and aspects of economic development in trans- border cooperation are insufficiently promoted". The Tourism Development Strategy of the Republic of Serbia was adopted in 2016. The Project aimed at the Support to Implementation of the strategy for tourism (2016-2025), funded by EU and performed in close cooperation with the Ministry of Trade, Tourism and Telecommunications as the main beneficiary, resulted in recommendations for updating “... the Strategy related policies in line with best EU practice".

From the perspective of cross sector approach and sustainability principles, the Strategy needs significant improvements. Sustainable development principles are not clearly present as guidelines and the foundation of the Tourism Development Strategy of Serbia. While natural values and protected areas are seen as important resources for tourism development, and its integrated management as one of the preconditions for its sustainability, it is not recognized as one of the key elements of tourism product branding. The expansion of protected area over the territory of Serbia may be considered as one of the measures of its biodiversity protection, and that is the only, indirect, link found in the Strategy between biodiversity and tourism development.

Involving of local community in planning, decision making and implementing of activities has been largely embedded in relevant international documents and requirements of EU policy. In Serbia, as in many other countries, this is reflected in all the documents regulating environmental and tourism sectors, including planning procedures. The Law on Free Access to Information of Public Importance, provides the platform for public participation relevant in many aspects for tourism development. 
The Law on Environmental Protection, as well as specific laws pertaining to the Strategic Environmental Assessment (Law on Strategic Environmental Assessment, RS Official Gazette Nos 135/04, 36/09, 43/11 and 14/16) and those covering planning procedures, bring to Serbian society new opportunities to be informed and involved in decision making on issues relevant for their everyday life, and to government institutions and project holders new, sometimes complex, responsibilities. In planning, as defined by Article 13 of the Law on Tourism, the Strategic Master Plan is a crucial document for "drafting spatial and urban plans at the priority tourist destinations and tourism areas" as these plans shall establish "conditions for the construction of tourism infrastructure facilities". However, it should be stated that the Law on Planning and Construction (Official Gazette of RS Nos. 72/2009, 81/2009 - correction, 64/2010 - decision of the CC, 24/2011, 121/2012, 42/2013 - decision of the CC, 50/2013 - decision of the CC, 98/2013 - decision of the CC, 132/2014, 145/2014, 83/2018, 31/2019 and 37/2019 - other act does not oblige the developer of the Plan to cooperate with the local community and civil society who live in the vicinity. (Petovar \& Jokic, 2017, p. 7) Also, one of the limitations for public participation in decision making in Serbia is a lack of experience and knowledge about techniques and methods, as well as insufficiently developed mechanisms and procedures for public participation in decision making.

However, it should be stated that in recent years initiatives have been taken to mobilize public awareness of various programs and actions for protecting the environment and implementing sustainable development strategies such as the Local Environmental Action Plans (LEAP) and Local Agendas (LA21). For these, strong support of local authorities and population has been reported, together with that of foreign donors. In strategies for tourism, rural tourism and natural resources development, there is a general awareness of community issues and their rights to public participation. There is a common understanding on the needs of the public to be informed and involved in the development. However, this is interpreted mainly as being confined to levels of information and consultation rather than to specific instruments and mechanisms of participation on an equal basis. In the documents in both sectors, the focus on "stakeholders", "public", local authorities or NGO (non-profitable) sector, is much stronger than on local communities and specifically targeted groups. Local community issues are directly incorporated into, and elaborated in the most successful manner within, the Draft National Strategy of Sustainable Use of Natural Resources and Goods and in the Draft Sustainable Rural Tourism Development Strategy. There is a general respect for local culture, but not directly related to the promotion of traditional knowledge in sustainable development and use of resources, or local communities sharing in economic and other benefits of tourism.

\section{Conclusions}

In a local economic development perspective, the interaction between tourism and community becomes fundamental. Tourism has become one of the most important industries. It is based on globalization and its role in the global development, whereas its dimension is local and it is connected with the local tissue of enterprises. Starting from a model of local economic development, institutions have to be aware of the problems and risks of a not well organized and sustainable program of intervention on the territory. Government intervention has to declare routes for the local economic development, especially for what concerns sustainability.

What characterizes local economic development in Serbia is an underdeveloped entrepreneurial culture, modest infrastructure that has not been invested in for years, insufficient financial capacity of local governments, inefficiency of local administrators, but also non-application of laws, by-laws and regulations that apply to the area of local development and high levels of corruption. Additional problems include: large number of fiscal and parafiscal charges, insufficient practical implementation of strategic documents in the field of economic development, underdeveloped institutional forms of local economic development offices, unresolved issues of local ownership and the non-use of bonds and securities by local authorities and incipient economic development instruments that have experienced enviable expansion in the modern world.

In order to achieve the goals of local economic development in an optimal way, it is necessary to respect the principles of depoliticization, professionalization, modernization and innovation when implementing the reforms of local administrative bodies. In countries where the quality of work of public authorities is relatively low, the quality of work of local administrations is generally even lower. The reform of the local administration in the cities, towns and municipalities in our country will ensure the efficiency of the public service system, reduction of costs and greater accessibility and quality of public services in tourism. Tourism is considered today a global industry, perhaps the largest in the world. At the same time its impacts and benefits are becoming more and more local, as more local is becoming the management of the revenues from its operation. 
Up to day, other activities which previously used to be included to other sectors of the economy, actually are being integrated in the operational chain of the touristic products and services by changing the way they are managed by getting closer to the final consumer. This creates a new local environment since it creates new perceptions and behaviors from both sides: operators and clients, local communities are more and more included in this chain in the role of providers, labor force and administrators. Local self-government creates a new local economy by playing a multiple role in it. Local communities learn not simply to evidence and use local natural and historical resources for their direct benefits, but also, they learn to evidence and promote the way of living, thinking and feeling as unique touristic offers by enlarging and transforming the product and service more root-based.

Tourism stakeholders must plan effectively now and be ready to adapt to change to leverage the opportunities that are said to arise. Local self-government is at the forefront of tourism delivery and in many ways the linchpin to other spheres of government, industry and the community. It provides an expanse of tourism infrastructure, from roads, to airports, ski centers, and parks just to name a few. Local Government in a tourism setting is governed by legislation from the State, from land-use planning through to environmental and health legislation; it is impacted by national tourism strategies, as well as other government strategies, and participates in, and contributes to the activities of tourism organizations and networks. Industry that supports tourism - accommodation, retail, restaurants, bars and cafes, all have reciprocal relationships with, and of course exist within local administration jurisdictions.

Local communities in various aspects of their economic development and management of tourism businesses need skills to provide better opportunities of employment in the tourism and hospitality sector. Under this optics, training institutions, professional center and universities must set up customer tailored study curricula to build up highly qualified and well-trained human resources in the public and private sectors. This to provide qualified human resources to develop, manage and serve the industry in a sustainable and competitive manner in accordance with international standards.

All this attempt will contribute the spirit of solidarity and support between operators at a local level, facilitate a better integration of the local touristic activity in a global scale, provide a better utilization of the revenues from tourism to improve local infrastructure and improve the economic performance of the region. The legal framework in different areas which in many cases in being restricted by agreements and geopolitics, the overall level of advancement in capacities and practices of local administrations, the level of integration of the touristic sector with the global industry, local features which imply specific behaviors and trends from operators and tourists in the area, interact and the outcome defines ways in which the sector can better serve as a real leverage to the sustainable local social and economic development.

In conclusion, we would like to emphasize the fact that decision regarding the improvement of effectiveness and efficiency of the touristic sector by improving the collection and management of local touristic tax, does not depend simply in the goodwill of local governors. 
ISSN 2661-2666 (Online) International Scientific Journal Monte (ISJM) DOI: 10.33807/monte.202004650

Volume 3 No. 1 (2020): April

\section{REFERENCES}

Alberti, F. G., \& Giusti, J. D. (2012) Cultural heritage, tourism and regional competitiveness: The Motor Valley Cluster, City, Culture and Society vol. 3.

Begović, B., Vacić, Z., Matković, G. \& Mijatović, B. (2016) Local economic development, Belgrade: Centre for liberal-democratic studies and Standing Conference of Towns and Municipalities.

Brooks, G. (2011) Heritage as a driver for development, ICOMOS Paris 2011.

Musaraj, A. (2016) Tourism development, touristic local taxes and local human resources, Enterpreneurship Training Center Albania.

Neskovic, S., Djelic, T. A., Antonovic, R., Lutovac, M. \& Ketin, S. (2020) Incorporation of Information Communication Technologies in Economic and Environmental Espionage, Fresenius Environmental Bulletin - FEB, Volume 29 - No 05/2020.

Pedrana, M. (2013) Local economic development policies and tourism-An approach to sustainability and culture, Regional Science Inquiry Journal Vol. V.

Petovar, K. \& Jokić, V. (2017) The right of servitude between public interest and undisturbed use of private property, SPATIUM International Review.

Rogerson, C., M. (2016) Tourism-LED local economic development: The South African Experience, Urban Forum.

Vasiljević, D. (2012) Local Economic Development, Belgrade: PALGO Center.

Wilson, J. \& Clavé, S., A. (2016) Geographies of Tourism: Europe Research Perspectives, Tourism Social Science Volume 19, Emerald. 


\title{
TOURIST ENTERPRISES, CONCEPT ON TOURISM DEVELOPMENT AND ITS ACCOUNTING
}

\author{
Prof. Dr. ANTONELLO FIGETTO ${ }^{1}$ \\ Prof. Dr. ALBA DUMI ${ }^{2}$ \\ 1"'Department of Management and Marketing, Roma University, Italy \\ Ministry of Economy, Roma Italy
}

\begin{abstract}
Nowadays, the tourist phenomenon involves millions of people moving from their permanent home to a temporary residence. To enable tourists to travel these people have different needs: for transport, sleeping, and for meals, etc. The sum of all these services is what we define as the hospitality industry, which is one of the world's leading economic activities. But what do you mean by economic activity? Economic activity is the coordinated and organized whole of all actions and actions to find the goods and services that are appropriate for achieving the goal. At the core of any economic activity lies the fulfillment of human needs. The need for tourism thus constitutes the core of the economic activity of enterprises operating in the field of tourism. Economic activity generally relies on four very interdependent moments: a) Finding the necessary resources for production. The first phase of this activity consists in providing the necessary factors for production, raw material, work, capital. b) The production of goods or services; The second phase that satisfies the needs consists in: the most appropriate combination of resources used; the transformation of goods and labor into finished products or services (accommodation, restaurant, travel packages, transportation services, etc.) Knowing the key financial concepts and the proper use of calculating and mathematical skills in personal finance situations are generally considered as a basic criterion for assessing a person as financially cultured. For this reason, the accurate measurement of these two criteria also constitutes one of the main objectives of the survey. This is to be achieved through a community of 8 well-studied questions that test respondents' knowledge on simple concepts such as: simple and compound interest, risk, return on investment, and inflation. In our analysis we will focus on the accounting system that provides users with both financial and non-financial information. Budgets, a tool often used, have been around for a long time. Operating budgets seem to be the most common. Although rarely used for their, potential, operating budgets are usually among the first budget budgets. The numbers for these budgets are not difficult to handle and most managers will give at least some confidence in their benefit. In the objectives of the paper, we will also consider how the internal user is oriented to use the accounting information and to use it straight to it.
\end{abstract}

11 Key words: Budget, operational data, Ministry of Finance in Kosovo, Empirical Study Accounting Empirical studies, interest, risk, Accountings politics

\section{JEL Classification Security System: N0, N1, N2, N3, O1, O2, O3. 1.1}

\section{Introduction}

Enterprises operating in the tourism sector are service enterprises, although in some cases they also show features that differentiate them from service companies. The activity of tourist enterprises is characterized by some elements that differ from the production activity of the goods where we mention:

-Intricacy of services (does not allow service judgment before consumption);

-Property storage (service that is not sold is considered a loss);

- The inability to transfer space services;

- Direct contact between the client and the staff; 
The production of tourist services supports two types of elements:

a) Physical elements, which are the material elements necessary for the production and the environment in which it is carried out.

b) Human elements, which in touristic enterprises play a major role not only at the moment of service production, but also in sales.

Tourist enterprises, especially hotels, are characterized by intensive and direct contact between the staff and the client. Measuring this contact is not simply given by the amount of time the staff passes with the client, but by the quality of the contact's own modalities. The latter provide an image for the enterprise to have a direct impact on its success or failure. The client's participation is very high in tourist activities due to the characteristics of tourist services and the level of involvement of human resources in the production of tourist services. Capital budgeting, however, does not fit well with many businessmen. This is partly due to the difficulties of preparing a capital budget. Cash flow assessments should be further delayed in the future and unfamiliar terms such as cost weighted average capital and internal rates of return, creep into terminology. Recent years academic studies have focused on emotions to explain the behavior of investors and the performance of financial markets. It should be noted that "Traditional finance theory" is built on the assumption that investors always make rational decisions having a single objective, maximizing the benefit in a risk environment and insecurity. The application of financial models means that individuals include information in the decision-making process using probability rules and statistics in calculations, leaving aside emotions. However, it should be noted that investors experience a series of emotions as they make a decision, and the more important this decision is, the stronger the emotions.

a) Calculations related to these terms are often unrecognizable; many businesses have learned to operate without a formal capital budget.

b) However, properly used, a capital budgeting process can help reduce the risk of making the wrong decision.

c) Capital budgeting is useful as a decision-making tool.

d) Accountants, and some staff and some managers, have probably been trained to make the calculations needed to determine the present.

e) Financial analyzes that have been made in the field of rational economic behavior generally do not take into account the role of emotions

\section{Methodology}

\section{Enterprise and Environment}

The tourism enterprise is a subsystem operating in a wider system, by which it performs a series of exchanges; the enterprise receives inputs from the external environment and supplies outputs in terms of goods and services. Efficiently administering an enterprise means knowing how to value inputs coming from abroad that are expressed in the form of opportunities (as a requirement) or rules (laws). The surrounding environment of the tourist enterprise is distinguished as follows:

- Natural and physical, cultural, technological, socio-political and economic resources;

-Register of used resources;

-The demand market for the services provided;

The assessment of the outdoor inputs should be the focus of the activity of the enterprise, since any positive or negative movement that is verified in the environment may influence the activity of the enterprise in the short or long term. The natural and physical environment is very important for the enterprise, and in many cases, it is the primary reason for choosing a tourist destination from the tourists. Likewise, the cultural environment has a determining role for the development of host enterprises in some localities, while the social, political, economic environment is more important in others. The technological environment influences production processes at the hotel (reservation or restaurant) by influencing the organization or the number of staff needed. However, it should be said that not all types of premises have the same degree of importance at the same time for the enterprise. The Scientific research work will become more accessible and easier if it is based on the relevant built-in and verified methodology. The methodology that will be used during the drafting of the paper will be 
based mainly on the domestic and foreign doctrinal points of view. Not only is this a lost opportunity for investors to benefit from precious stocks in the market, but market exit at its low points hurt investors when they "sell less" and see no returns on their investments. 2.1 The negative and positive emotions. Albania's population is younger than that of other European countries. A third of its 3.1 million inhabitants is under the age of 15, and $40 \%$ is younger than 18 . The population grew by $1.2 \%$ per year in the period 1980-1999, with a fertility rate in 1999 of 2.4 children per woman of childbearing. The country experienced even higher population growth in earlier decades, encouraged by the policy of the Communist regime. A high proportion of Albania's population lives in rural areas, amounting to $58 \%$ in 2001 . However, since restrictions on freedom of movement were lifted in the 1990s, there has been a level of internal migration from rural to urban areas, that is unprecedented in Albania. In 1979, only $33.5 \%$ of the population was urban. This figure rose to $35.5 \%$ in 1989, and in 2001 it reached $42.1 \%$. Due to this influx, the population in the district of Tirana While negative emotions prevent us from benefiting from the market, positive ones make us very optimistic; we forget to do things like keeping our low tariffs, thinking about our risk tolerance, or keeping an eye on diversification. Economic analyzes that have dealt with rational economic behavior have largely disregarded the role of emotions Regardless of research on emotions, the description of the term "emotion" is defined very rarely.

\section{Methodology}

This paper upon the characteristics and features it carries is based only on the qualitative method of analyzing the issues addressed in it. It aims to answer the questions: How? Why? What's the way? 2.2 Decision making process and importance of Constancy In the traditional literacy and decision-making literature of a decision is mainly treated as a cognitive phenomenon and conceptualized as a goal or final point for a more complex process of reflection, which includes an assessment of the consequences and uncertainties. (Parkin 1996) determined the variables of a personal decision-making process consisting of five phases: Defining the Problem; thinking; trial; decision; and action. Parkin identified the impacts commonly affecting this process, such as behavioral history, beliefs, and situations. With all the research done today that includes emotions and choices, it is difficult to ignore the fact that emotion drives decision-making

\section{Literature Review and Hypothesis}

Researcher and Professor Svenson (1996) distinguished four levels of decision-making. The first level of decision-making processes involves many quick and mostly automatic and unconscious decisions. The decisions taken with respect to one or more attributes that favor the elected candidate belong to the decisions second level. The third level means that decision-making is a process that refers to choices between alternatives in relation to conflict of intent. People can believe that their knowledge is more accurate than what they really are, may think that their skills are above the average can have an illusion of control or may be too optimistic about the future. Thus, aspects of others are taken into account when making decisions in uncertainty and people are more affected by perceived risk than objective risk (Diacon \& Ennew, 2001). Risk perception is an indispensable component of financial decision making and other risk-taking behaviors It is also necessary to make a distinction between risk and risk events.

\section{Research Goal Analyze}

The tourist product cannot be classified as split apart from other activities; it is considered as a multiple mix of activities that are of interest to all economic sectors. We say this by considering the fact that tourism is linked to other economic activities by assessing the impact of the tourism sector on the national economy, its impact on the balance of payments, the assessment of tourists' expenses and other variables measured not with much difficulty. Through the method of analysis, I intend to analyze the native and international legislation in place for the regulation of legal relations. In psychology, risk is perceived as a subjective construct influenced by the way an event is interpreted. Therefore, perceived risk differently from different people in different contexts. An analysis of how people make investment decisions confirm that objective probability estimates have only a weak impact on the decision-making process. Risk is defined as the probability of decision results in the context of expected service theories, which are applied to understand financial decision making. In 2017, the GOA initiated a comprehensive reform of the health system. This led to a change in the method of funding providers, and began the transition of HII to a single-payer. This was followed by steps to consolidate the PHC budgets in HII, and to allocate it by region, and then to allocate it by Health Center. The Director of the HC (as well as a Board) would be responsible for managing the funds in the bank accounts for each HC. A contract process was designed 
between HII and each HC to specify the package of services to be provided in the HC in order to receive payments from HII. (National Health Accounts (NHA), Albania, July 27, 2010)

Hypothesis 1. A part the subjective elements the evaluation was also based on objective ones, related to the work quality, the work results and professional know ledges etc.

Hypothesis 2: With all the efforts of avoiding the subjective elements there still wasn't a correct evaluation.

Hypothesis 3: The final evaluation, which was completed by the head of the institution, included the general evaluation with points, the general evaluation in words, proposals for further qualifications based on the evaluations, and also the head of the institution giving ideas of a different leveled job.

\section{Reforms and public administration standards}

Technological evolution and fast-paced social development have transformed manners for vacation and human tourism nowadays. His demands for accommodation have also become more and more different. The ease of moving enables them to frequently frequent distant lands, with different habits and so he faces these services and sometimes judges them critically. Thus, each type of host activity should give a precise identity according to modern hospitality requirements according to different typological characteristics.

The laws directly or indirectly discipline this activity to guarantee the tourist with a system that respects the comfort, hygiene, quality and the right number of services. The typological classification determines these types of host structures. In 1998, the ministers of community places concluded the fields and most important of intervention for the modernization of the public administration. These directions were:

1. A better improvement through laws and norms

2. The use of the public services standards for the society

3. Full using of the electronically systems

4. Placing the competition system in accomplishing the duties

5. The forming of the public functionaries

On the other side, these elements would serve Albania to create a public administration based on the standards, which our country should have aimed for and realize them for the integration into the European Union.

- The state role

- The relationships of the government with community

First, the role of the state means passing not only from a state that offers services, but into a state which fixes and guarantees services and within the logic of management and economical judgments against the logic of autocratic structures, aiming the satisfactions of the society. (Public administration, Koxhaj A, 2002).

a) One of the most significant indicators of high-quality living has been the ever-growing use of leisuretime tourism.

b) Along with the effects it has had over these years in culture, environment, lifestyle etc; often it has been a major factor in economic growth, social growth, or development of a destination in general.

c) More and more destinations are interested in understanding the role of different factors and their participation in future tourism developments.

d) By analyzing the positive and negative effects of any factor, any destination or touristic organization can use them in favor of developing new tourist products, creating more income and more sustainability in the future.

\section{Conclusions}

It should be emphasized that hospitality is not an exclusive object of their activity, as they can also provide material benefits, such as restaurant activity or other types of services. The primary object of the host enterprises 
is the production of accommodation service, the presence of other services is complementary and completes their product, satisfying and meeting the different needs and requirements of the clientele, while increasing the enterprise's ability to provide income. The association between successful delivery and bureaucratic performance is difficult to identify and has led to an increasing interest in establishing the relationship between bureaucratic performance and development outcomes. In the case of Pakistan, measures to augment the bureaucratic performance entail civil service reforms over the past decades. The reform has led to a system in which performance is supposed to be evaluated but these reforms have had little impact on actual performance. (Hussain, 2007; Tanwir 2010). The reason for this can be two-fold: Either the reformers may have implemented the wrong types of reforms or the civil servants may be resistant to reform since they feel that the present system is optimal for them and have created roadblocks for its implementation. We argue that the one of the possible reasons for this lack of impact might be because the civil service reformers have failed to fully understand the various performance evaluation systems, which in turn means that the system that has been implemented is the wrong one. We also find that the majority of bureaucrats recognize that the present system is flawed and would be willing to accept a revised system that accurately measures and rewards performance. In this article we look at the various models of performance management systems and narrow down the performance evaluation system that best fits the context. The evaluation of the performance is determined as an evaluation of the past and actual performance of an administration employee according to the standards organization performance. The process of evaluation of the performance consists on:

1.The work standards.

2. The evaluation of the actual employee's performance related to these standards 
ISSN 2661-2666 (Online) International Scientific Journal Monte (ISJM) DOI: 10.33807/monte.3.201912491

Volume 3 No. 1 (2020): April

\section{REFERENCES}

Drucker, Peter F. The Future of Industrial Man. New York: John Day, (1942). Drucker, Peter F. Concept of the Corporation. New York: John Day, 1946; revised edition, 1972. Title of British edition: Big Business. London: Heinemann, 1946.

Drucker, Peter F. The New Society. New York: Harper \& Row, (1950). Eells, R.S.F. and Walton, C.C. Conceptual Foundations of Business. Homewood, Ill.: Irwin, 1961.

Emmett, B., and Jeuck, John C. Catalogues and Counters (1950). A History of Sears, Roebuck \& Co. Chicago: University of Chicago.

Maslow, A.H. Motivation and Personality. New York: Harper \& Row, (1954). Mayo, Elton. The Social Problems of an Industrial Civilization. Boston: Harvard Business School, 1945.

Mayo, E. (1946). The Human Problems of an Industrial Civilization. Boston: Harvard Business School.

McGregor, D. (1960). The Human Side of Enterprise. New York: McGraw-Hill.

Taylor, F.W (n.d). The Principles of Scientific Management. New York: Harper's, 1912, and many editions since.

Wiener, N. (1950). The Human Use of Human Beings. Boston: Houghton Mifflin.

Woodward, J. (1965). Industrial Organization; Theory and Practice. Oxford University Press.

DCM no. 66, 03.02.2017, "On defining the criteria and the procedures for the establishment of medical university services and structures"

DCM no. 109, 15.02.2017, "On organization and performing of the Agency of Quality Assurance in Higher Education (AQAHE) and Accreditation Board (AB) and defining the fees of quality assurances processes in higher education" 


\title{
COST METHOD EFFECTIVENESS ANALYSES CASE STUDY - FIXED TELECOMMUNICATION IN ALBANIA
}

\author{
Brikena Tolli \\ Marin Barleti University, Tirana, Albania \\ brikenatolli@gmail.com
}

\begin{abstract}
The fundamental problem in the Telecommunications market, which contributes to slowing down the competition, reclines in the local and central necessary network access, capable to offer regulated services. In order, to overcome to stimulate competition in the telecommunications market effectively, the European Commission intervened with a series of directives forcing the only notable operators who own the network, to provide regulated access. This regulation was then extended to all of the operators with the significant market power. The national regulatory authority is the authority that determines the right access price to encourage downstream competition and at the same time encourage the prospects of new operators to build their own infrastructure. Different methodologies are used to allocate costs for calculating access prices by national regulatory authority in European countries. They use accounting methods, preferring them over what economic theory advises, however these methods are affected by a variety of limitation. The telecommunications sectors in Albania comprise a similar situation that deserves the attention of operators, regulators and academics. This sector is subject to ex ante regulation and access regulation is of public interest. It is therefore of strategic importance to find the right balance between promoting competitions in the short term - allowing new operators to enter in the market - and promoting long-term competition through appropriate incentives to invest in alternative infrastructure. The research is based in qualitative method. There is no information on the costs of operators and their calculations but a qualitative analysis of the collected facts as well as a qualitative analysis of the author based on her background. Primary sources are obtained from documents published by the regulator and operators, legal and sub-legal acts; secondary data are collected from various scientific and professional articles and publications of academics and researchers, also books and regulatory documents of other countries. Electronic and Postal Communications is the Albanian regulator Authority that verifies the compliance of the regulated rates with the method and conditions set for the regulation of the rates. Even though since 2010 the Albanian regulatory has formally accepted the application of the Bottom-up Long-Run Incremental Cost method, it continues to apply a Benchmark model with reference to the rates calculated by the regulators of the Body of European Regulators for Electronic Communications countries. So there has been no evidence of data being used to do a complete research in order to decide whether the results obtained by using the Benchmark model would have been more / less consistent and more / less efficient than those obtained from using the Bottom-up Long-Run Incremental Cost model (cost-oriented model). The author concludes that the regulatory complies with the requirements of the law, but with limited application, it implements the minimum / maximum average rate model of Body of European Regulators for Electronic Communications countries with a gradual correction (glide path). The implementation of bottom-up LongRun Incremental Cost method would be the best way to reduce the fixed network termination/transition rates thus promoting competition. The regulatory should carry out a full study on the calculation of termination/transition rates according to the pure Bottom-up Long-Run Incremental Cost method and also should prepare a manual of procedures for operators with significant market power on how to identify their costs.
\end{abstract}

Key words: Telecommunication, interconnection rates, cost methodologies, BULRIC, AKEP

\section{Introduction}

The majority of European Countries have managed the services of the network industries under a monopoly regime. In particular, referring to the telecommunications market, technological development - especially of microelectronics, information technology and with the introduction of optical fibre - has had a significant impact on the reduction of average production costs, on the exhaustion of economies of scale in some stages of the production chain and consequently barriers to entry in the market have been reduced. Therefore, the conditions were created to be able to introduce competition also in this sector. The European Commission has been the great promoter of radical changes. In order to be able to stimulate competition in the telecommunications market 
effectively, the EC intervened with a series of directives forcing the only historical operators who own the network, to provide regulated access. The obligation to give access is underlined by the fact that the refusal of access constitutes an abuse of a dominant position according to art. 102 of the TFEU ${ }^{1}$. The Commission also encouraged member states to set up national regulatory authorities, legally separated from both telecommunications providers (avoiding the capture of the regulator by the letter) and from the government, with the power to set tariffs and monitor the situation of the entire telecommunications sector. It is the responsibility of the regulatory sector to sets the right access price.

In Albania, the Tlc sector is regulated by the Electronic and Postal Communications Authority (AKEP), which operates under the law no. 9918 dated 19.05.2008 "On Electronic Communications in the Republic of Albania" which sanctions the duties and responsibilities of AKEP in Article 7, 8, and 9. This paper aims to bring the author's critical perspective to the methods of setting fixed network interconnection rates used by the regulator in the regulated markets.

The limits of this paper refer to: low number of interviews; small number of consulted documents; limited number of parameters obtained in the analysis that might affect the quality and competitiveness of the operators. The author encourages all academics and researchers in the field to expand their research beyond the limits recognized by the author in this paper.

\section{Literature Review}

In the early stages of liberalization, ex-ante regulation was indispensable for opening up the market, while ensuring that new entrants were not penalized by the benefits that incumbents enjoyed. It falls under European Commission to issue the directives as guidelines for the regulation to which the Tlc markets are subject at the European level. Obviously, the regulation also called asymmetric regulation must last until disparities in the market are eliminated, that way not supporting the survival of an inefficient operator in the market. (Martellini, 2007).

Access regulation is in itself a bit ambiguous as it reduces the entry barriers for new entrants, allowing them to use the network of the former monopolist, thus increasing competition. One the other hand, it reduces incentives to build an alternative infrastructure similar to the former monopolist by sacrificing dynamic efficiency. Hence, there is a tension between promoting downstream competition through regulating upstream access, and competition between upstream activities. (Hellwing, 2010).

In the Commission's opinion (according to the EC), if access to the network was guaranteed, nothing prevented the market from being competitive ${ }^{2}$. According to the directive ${ }^{3}$, companies with significant market power are obliged to provide access to a cost-oriented regulated price (according to the principle of transparency, nondiscrimination and equity). It is up to the regulator to set the right access price to encourage downstream competition and in the same time encourage the prospects of new operators to build their own infrastructure. The right price must not allow an inefficient operator to enter the market and must not allow the incumbent operator to squeeze the profit margins of the equally efficient new operators, excluding them from the market. The Commission directives require that interconnection and access rates should be based on costs, leaving a fair return on the capital invested, but not specifying the methodologies for calculating these costs or the level of fair return. (Gual \& Jòdar-Rosell, 2009).

Different methodologies for allocating costs to calculate access prices are used by European countries which still remain unaligned ${ }^{4}$. According to economic theory, there are two schools of thoughts to determining network

1 Official Journal of the European Union. Consolidated versions of the treaty on European Union and The treaty on the functioning of the European Union (2008/c 115/01), Article 102.

${ }^{2}$ Directive 97/33 / EC of the European Parliament and of the Council of 30 June 1997, on the interconnection in the telecommunications sector and aimed at guaranteeing universal service and interoperability through the application of the principles of supplying an open network (ONP) .

${ }^{3}$ Directive 2002/19 / EC of the European Parliament and of the Council, of 7 March 2002, relating to access to and interconnection of electronic communications networks and related resources (access directive). Art. 1

${ }^{4}$ Brussels, 12.11.2018 SWD(2018) 463 final Commission Staff Working Document Evaluation Report on the Commission's 2009 Recommendation on Termination Rates (Recommendation 2009/396/EC) 
access prices that take economic principles into account, namely, "the efficient component pricing rule - ECPR ${ }^{5}$ and the approach evoked by the Ramsay ${ }^{6}$ principle. However, regulators have preferred to focus on the use of accounting methodologies to solve the problem, by neglecting the considerations related to market demand and supply. Among the methods mainly used by the Tlc sector regulators, we can name the following:

- The first is the method of fully distributed costs (FDC). It takes into account all the costs incurred by the company. The total cost attributed to the access network, and also the price, is equal to the sum of costs directly attributed to each component of the network and the fraction of the common costs attributed to each component. Similarly, the access price is also calculated as the sum of the prices of each component. (Marzi et al., 2001).

- The second is the long run incremental cost (LRIC) method ${ }^{7}$. It is the method of use, which the Commission recommended in the 2002 directives, in order to eliminate the inefficiencies of the former monopolist. It is not based on the historical costs of the former monopolist company, but on the costs of an alleged efficient new operator who uses the most efficient technology of the moment to produce the same services as the former monopolist. For the calculation of these costs is used the randomness criterion, which relates the cost to the reason itself. This method is based on current costs where the network components are valued at fair value.

- The third is the Retail method - minus a form of ECPR. According to this methodology, the access price is imposed equal to (1-x) \% of the retail price. The incumbent is free to set the retail price and consequently the upstream access price is fixed by subtracting the avoidable costs (CE) incurred by the incumbent from the retail price. By definition, this method is not cost-oriented ${ }^{8}$.

However, in recent years it can be seen that the regulation of voice termination in fixed networks has led to a marked general decline in tariffs, although this is less than the decline in tariffs in the mobile network sector ${ }^{9}$.

\section{Methodology}

Methodology of the research is composed of following steps:

Sampling (limited number of operators as well as regulators);

$>$ Qualitative research method (in the paper there is no information on the costs of operators and their calculations but a qualitative analysis of the collected facts as well as a qualitative analysis of the author based on his background.)

$>$ Data: (primary sources are obtained from documents published by the regulator and operators, legal and sublegal acts; secondary data are collected from various scientific and professional articles and publications of academics and researchers, books and documents of regulators of other countries)

\section{Findings, Analysis and Discussions}

The sample created for the purpose of the study consists on the operators in the telecommunication sector, the number of which is limited in Albania. The data and reports taken into account are collected from Albtelekom, Telekom Albania and Vodafone Albania.

\footnotetext{
${ }^{5}$ Considering a liberalized market where the incumbent is integrated vertically, this rule starts from the assumption that the retail price is fixed in advance by the regulator. At this point, the access price will only affect production efficiency, i.e. the entry of new operators into the market. The regulator must set an access price that minimizes production costs to achieve production efficiency. (Cambini et al. 2000)

${ }^{6}$ The access price and the retail price of the network owner are fixed simultaneously. This model offers a better solution in the presence of fixed costs by encouraging both the entry of new efficient operators and investments in new infrastructures. Cambini, Ravazzi, Valletti. (2000).

${ }^{7}[. .$.$] The long-term incremental cost is the cost determined by a significant increase in the output produced with the use of the$ most efficient technologies in such a time that all production costs can be considered variable [...]; Resolution no. 258/02 I CONS; Public consultation on the introduction of an incremental cost accounting methodology for notified operators of fixed and mobile networks; Official Gazette of the Italian Republic of 19 August 2002, n. 193

${ }^{8}$ OECD Reports Access Pricing 2004. Access Pricing in Telecommunications. This report on access pricing and the regulation of access services was adopted by the Competition Committee in 2004.

${ }^{9}$ BEREC Annual Reports for 2018, 13 June 2019.
} 
By decision of AKEP No. 74, dated 1.10.2018 "On the approval of the document: regulation of tariffs for SMP entrepreneurs in wholesale fixed network terminating and transit calls" it is specified that such operators as Albtelekom Ltd, Telekom Albania Ltd and 67 other operators are those with significant market power (SMP) in the fixed telephone sector. From the information provided by official publications ${ }^{10}$, Albtelekom is SPM with the following indicators:

- $100 \%$ of the market share of call termination to network subscribers.

- $99 \%$ of the market share for national call volume.

- Revenue from transit of these calls is $90 \%$

In evaluating the SPM, AKEP has considered of great importance the market shares, the countervailing power of service buyers, and the termination service rates. (AKEP Decision No. 21, 2018).

These operators are subject to regulatory measures for the termination and transition service of calls in fix network. The Law No. 9918, dated 19.5.2008 (as amended) "On electronic communications in the Republic of Albania", regulates the promotion of competition and efficient infrastructure in electronic communications through the principle of technological neutrality. The Article 57 of the Law also regulates the methods of setting rates for operators with SPM. AKEP is the regulator defined in this law that verifies the compliance of the regulated rates with the method and conditions set for the regulation of the rates.

The interviews with AKEP officials and the review of public consultation documents published by AKEP show that since 2010 the use of the BULRAIC method for fixed telephony has been formally accepted, whereas for Bit stream access the Retail + method was used until 2016. Since then, this method has undergone a significant change by being replaced by $\mathrm{x} \%$ reduction of the maximum and / or minimum Bit stream access fee. From the interviews with AKEP officials and ex-officials resulted that applying the BULRIC method turns out to be difficult and cost effective, therefore, currently it is used an alternative technique of a rate adjustment according to a Benchmark level and their escalation reduction (glide path).

The data and reviewed literature show that using Retail + allows the SPM operator is free to choose the retail price and as a result, it enables it to control the entire market. The choice of such a retail price enables it to remove competitors from the market or compress their profit margin. AKEP's motivation to have used the Retail + method until 2016 is considered unjustified. The justification for using this method, namely to preserve the relevance of the final prices, which are certainly not under discussion, without however considering whether such relevance would not have been even better assessed by a cost orientation model for all access services.

Even though since 2010 AKEP has formally accepted the application of the BULRIC method, it continues to apply a Benchmark model with reference to the rates calculated by the regulators of the BEREC countries. So there has been no evidence of data being used to do a complete research in order to decide whether the results obtained by using the Benchmark model would have been more / less consistent and more / less efficient than those obtained from using the BULRIC model (cost-oriented model). The glide path is applied to avoid problems to existing market operators and their finances through an abrupt reduction of termination/transition rates that result from the application of benchmarking rates. The use of a Benchmark model, even escalating in time, does not reflect the differences that exist between the BEREC countries and Albania. The Application of Benchmark model would require the calculation of a correction coefficient of the economic characteristics between Albania and the BEREC countries. Among the most notable differences, we can mention:

○ relatively small market compared to most European Community countries;

$\circ$ technological development in the telecommunications sector;

$\circ$ the purchasing power of the final consumer.

Also, the use of the "Glide path ${ }^{11 "}$ of tariffs, although encouraging operators to invest due to a higher return on investment (as long as it lasts), prolongs the inefficiency effects that produce the Benchmark model tariffs. In other words, instead of the AKEP work on the implementation of the BULRIC method of rate setting, it simply

${ }^{10}$ DECISION No. 21, dated 30.3.2018 “On Document Adoption. Market analysis of fixed telephony: Wholesale market in termination/transits call in Public Fixed Telephone Networks, Final Document" and the 2018 Annual Activity Report, AKEP ${ }^{11}$ Malaysian Communications and Multimedia Commission, Review of Access Pricing, Public Inquiry Paper, 6 October 2017 
wastes time in escalating a rate that is inefficiently calculated, thus causing financial harm to key market players and their finances. Combining Benchmark with Glide path, strays further away termination/transition rates from an efficient result obtained using cost-oriented rates.

During 2017-2019, the applied reduction is $23 \%$ and by December 2019, the applied reduction is $46 \%$. The Benchmark level takes into account the average of the maximum/minimum rates level applied by BEREC country regulators including $28 \mathrm{EU}$ countries and 9 other countries in the region. In the market analysis of fixed telephony carried out by AKEP in 2015 (AKEP Decision No. 2617, 2015), it emerges that the average level of the maximum/minimum rates in the BEREC countries is higher than the average rates of these countries referring only to the rates calculated using the Pure BULRIC method. The method of maximum/minimum average rate of BEREC countries remains controversial to be applied by AKEP not only because of the higher rate value this method produces but also because of the fact that rates are not corrected by differences existing between BEREC countries (whose rates are used for Benchmark) and Albania. According to the law no. 9918, dated 19.05.2008, article 57, paragraph 1, iii), AKEP, in setting rates, is obliged to orientate in the determination of rates according to efficient costs that enable a reasonable profit. The application of the LRIC method is entirely in accordance with how it is required from the law. This method would require from AKEP the application according to the graph below ${ }^{12}$ :

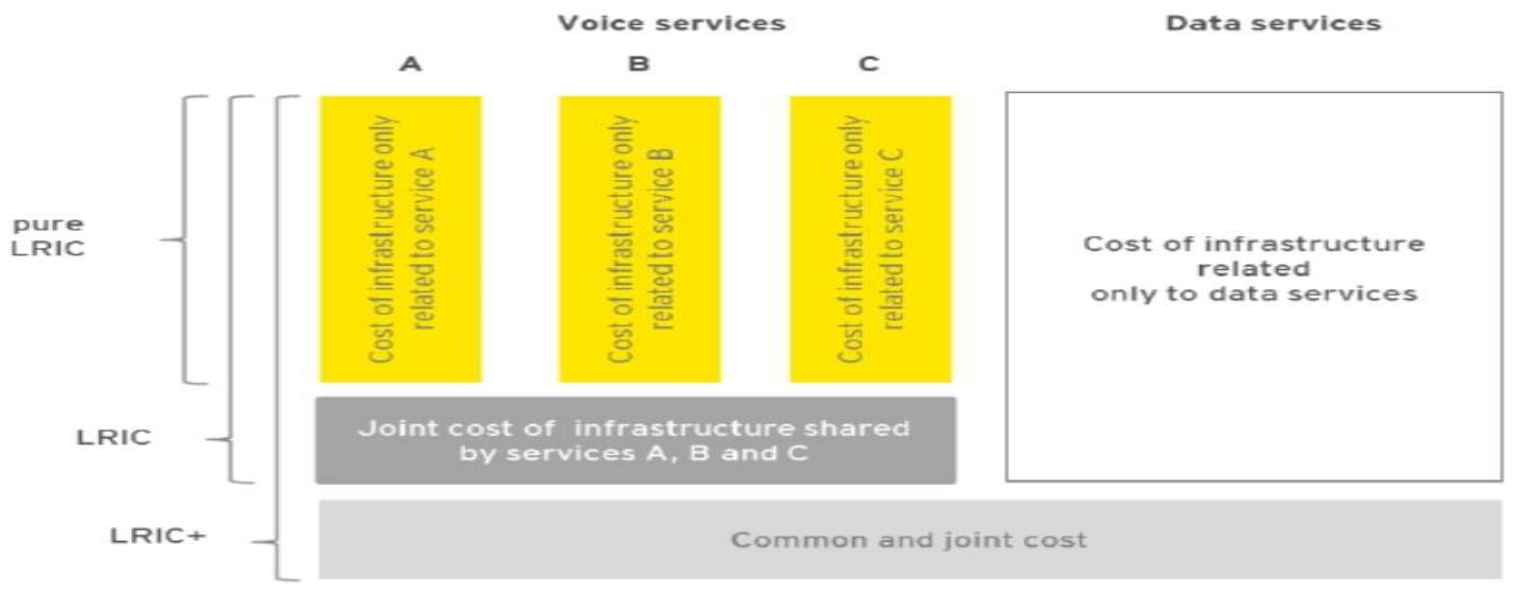

To accurately identify costs, it is required the establishment of the expertise groups (economists and engineers). In their task, these working groups operate in accordance with the Bottom-Up approach of all network costs faced by an efficient operator. This approach provides the following steps:

- Dimension and revaluation of the network;

- Estimation of the network costs;

- Estimation of the non-network costs;

- Estimation of the operating maintenance and supporting costs;

$\circ$ Estimation of the services costs. ${ }^{13}$

It would be cost-effective to invest energy, human resources and financial values in calculating BULRIC costs not only to comply with the law but also with the EU recommendations. It is economically proven that using the BULRIC method leads to the determination of lower rates by:

- Helping to reduce entry barriers for new operators;

- Promoting competition in the wholesale markets;

- Creating an advantage for final consumers.

${ }^{12}$ BU-LRIC methodology, Fixed network, Version 30-09-2015, EY, Building a better working world. 
ISSN 2661-2666 (Online) International Scientific Journal Monte (ISJM) DOI: 10.33807/monte.202004655 Volume 3 No. 1 (2020): April

\section{CONCLUSIONS}

AKEP complies with the requirements of the law, but with limited application, AKEP implements the minimum / maximum average rate model of BEREC countries with a gradual correction (glide path).

The Operators require AKEP to apply for the determination of interconnection rates a cost-based method and specifically the pure BULRIC method. The implementation of this method would significantly reduce the fixed network termination/transition rates thus promoting competition.

Applying this method for AKEP is expensive in terms of logistics, human and financial resources.

\section{RECOMMENDATIONS}

1. AKEP should carry out a full study on the calculation of termination/transition rates according to the pure BULRIC method and also should prepare a manual of procedures for the operators with SPM on how to identify their costs according to the table given on the page 7.

2. The provision of detailed costs by operators with SPM to AKEP's needs would facilitate the application of pure BULRIC model from the AKEP and would reduce the financial burden for applying this method.

3. AKEP should conduct a public consultation with stakeholders on the new rate calculation approach aiming to involve stakeholders in the process. 
ISSN 2661-2666 (Online) International Scientific Journal Monte (ISJM) DOI: 10.33807/monte.202004655 Volume 3 No. 1 (2020): April

\section{References}

AKEP (2018). Raporti vjetor i veprimtarise 2018. Retrived from https://akep.al/wpcontent/uploads/2018/09/AKEP-RAPORT-VJETOR.pdf

AKEP. (2018). Vendim Nr. 21, datë 30.3.2018 Për miratimin të Dokumentit: Analizë e tregut të telefonisë fikse: tregjet me shumicë të terminimit dhe tranzitimit të thirrjeve në rrjetet telefonike publike fikse Dokument përfundimtar. Retrived form https://akep.al/wpcontent/uploads/images/stories/AKEP/publikime/2018/Vendim_nr.21_date_30.03.2018.pdf

AKEP. (2018). Vendim Nr. 74, datë 1.10.2018 Për miratimin e dokumentit: Rregullimi i tarifave të sipërmarrësve me FNT në tregjet me shumicë të terminimit dhe tranzitimit te thirrjeve në rrjetet fikse. Retrived from https://akep.al/wpcontent/uploads/images/stories/AKEP/publikime/2018/Vendim_nr.74_date 1.10.2018_Miratimi_i_dok umentit_final Rregullimi_i_FTR.pdf

AKEP. (2015). Vendim Nr. 2617, datë 8.10.2015 "Për Miratimin të Dokumentit: Analizë e tregut telefonisë fikse: tregjet me pakicë dhe tregjet me shumicë të terminimit, tranzitimit dhe origjinimit - Dokument Përfundimtar" Retrived from https://akep.al/wpcontent/uploads/images/stories/AKEP/GALERI/Vendim-Nr2617date8102015.pdf

BEREC. (2019). Annual Reports for 2018. Retrieved from file:///C:/Users/User/Downloads/8598-berec-annualreports-for-2018 0.pdf

BEREC. (2017). Termination rates at European level July 2017. Retrieved from file:///C:/Users/User/Downloads/7524-termination-rates-at-european-level-july 0.pdf

Cambini C., Ravazzi P. e Valletti T. (2000). La tariffazione dell'accesso nelle telecomunicazioni: Principi economici e interventi regolatori in alcuni paesi industrializzati. Working Papers form ICER. Retrieved from https://www.bemservizi.unito.it/repec/icr/wp2000/Cambini10.pdf

Cambini C., Ravazzi P. e Valletti T. (2000). Regolamentazione e mercato nelle telecomunicazioni. Roma, Italy: Carocci Editore.

European Commission. (2018). Commission Staff Working Document. Evaluation Report on the Commission's 2009 Recommendation on Termination Rates (Recommendation 2009/396/EC). SWD(2018) 463 final. Brussels: European Commission.

European Commission. (2017). Europe's Digital Progress Report 2017. Connectivity. Broadband market developments in the EU. Retrived from file:///C:/Users/User/Downloads/EuropesDigitalProgressReportConnectivityChapter.pgf

EY (2015). Building a better working world. Version 30-09-2015. BU-LRIC methodology, Fixed network. Retrieverd from https://www.gncc.ge/uploads/other/2/2734.pdf

Gazzetta Ufficiale della Repubblica Italiana (2002) Delibera n. 258/02/CONS; Consultazione pubblica sull'introduzione di una metodologia di contabilità a costi incrementali per gli operatori notificati di rete fissa e mobile; Gazzetta Ufficiale della Repubblica Italiana del 19 agosto 2002, n. 19.

Gazzetta ufficiale delle Comunità europee. (1997). Direttiva 97/33/Ce del Parlamento Europeo e del Consiglio del 30 giugno 1997, sull'interconnessione nel settore delle telecomunicazioni e finalizzato a garantire il servizio universale e l'interoperatività attraverso l'applicazione dei principi di fornitura di una rete aperta (ONP).

Gazzetta ufficiale delle Comunità europee. (2002). Direttiva 2002/19/Ce del Parlamento Europeo e del Consiglio del 7 marzo 2002, relativa all'accesso alle reti di comunicazione elettronica e alle risorse correlate, e all'interconnessione delle medesime (direttiva accesso). Art.1.

Gual J. and Jòdar-Rosell S. (2009). European telecoms regulation: Past performance and prospects. in Competition policy in the EU. Xavier Vives. Oxford University press.

Hellwing, M. (2010). Competition Policy and Sector-Specific Regulation for Network Industries', in Completion Policy in the EU, Xavier Vives. Oxford University press 
ISSN 2661-2666 (Online) International Scientific Journal Monte (ISJM) DOI: 10.33807/monte.202004655 Volume 3 No. 1 (2020): April

Ligj Nr.9918, datë 19.5.2008 (I ndryshuar) Për Komunikimet Elektronike në Republikën e Shqipërisë. Neni 7,8,9 dhe 57. In https://akep.al/wpcontent/uploads/images/stories/AKEP/legjislacioni/ligji9918ndryshuar-versioni-publikimweb190313.pdf

Malaysian Communications and Multimedia Commission. (2017). Review of Access Pricing, Public Inquiry Paper. Retrieverd from https://www.mcmc.gov.my/skmmgovmy/media/General/pdf/PI-Paper-Reviewof-Access-Pricing-2017.pdf

Martellini, M. (2007). Dal monopolio alla concorrenza. La liberalizzazione incompiuta di alcuni settori. (pp. 190-240). Milano, Italy: Franco Angeli.

Marzi G., Prosperetti L. e Putzu, E. (2001) La regolazione dei servizi infrastrutturali. Bologna, Italy. Il Mulino.

OECD (2004). OECD Reports. Access Pricing 2004. Access Pricing in Telecommunications. France. Retrieved from http://www.oecd.org/regreform/sectors/27767944.pdf

Official Journal of the European Union. (2008). Consolidated versions of the treaty on European Union and The treaty on the functioning of the European Union (2008/c 115/01), Article 102. 


\title{
OPERATING BUDGETS AND THE TURISTIC TRAFFIC PATTERNS AND THEIR IMPORTANCE.THE GOVERNMENT AND OTHER STAKEHOLDERS OF TOURISM.THEORETICAL TREATMENT ANALYSIS
}

\author{
PhD (Candidate) FRANKO BAGNIOLINI \\ University of Roma, Italy \\ Department of Finance and Accounting, Roma University, Italy
}

\begin{abstract}
Tourism development could be even bigger if more could be done in various elements of transportation systems. It is an important for all its stakeholders to take part to develop tourism in their regions. Tourism sector is one of the main important sectors of the economy. Many countries take advantage of covering the budget deficit with the help of profits coming from tourism. That is why tourism sometimes is called a factory without chimney. But tourism has its own unique features that differentiate this sector from the others. Like in the other service industries, in tourism the customers, that is, the tourists come to the destination where the tourism services are provided. As the matter of fact, it is difficult to think of tourism sector without transportation. Transportation is the main mean to carry passengers, that is, the tourists to the actual site where tourism services are performed (Mudsuman P) In the first models of tourist systems, the emphasis is placed on the components of the two regions' connectivity: that of tourism and the reception of tourists. Researcher Marioti, for example, proposes three routes for the movement of tourists from their permanent residence (origin) to the tourist region (destination), which are the entrance and exit routes, which in some cases coincide with each other and the entertainment route. While access and exit routes ensure the connection between the two countries, the entertainment route on the other hand ensures the use of touristic structures during travel even though these structures do not belong to the tourist destination. As we have noticed before, an effective accounting system is vital to the firm's success. Without the information provided by the management accounting system cannot make decisions. However, the quality of a firm's accounting system depends on the effectiveness of internal control within the firm. Internal control is a system of controls and balances that plays a key role in maintaining the firm's assets and in reinforcing the accuracy and security of financial reports. The importance of internal control is great in large corporations. Knowing the key financial concepts and the proper use of calculating and mathematical skills in personal finance situations are generally considered as a basic criterion for assessing a person as financially cultured. For this reason, the accurate measurement of these two criteria also constitutes one of the main objectives of the survey. This is to be achieved through a community of 8 well-studied questions that test respondents' knowledge on simple concepts such as: simple and compound interest, risk, return on investment, and inflation. In our analysis we will focus on the accounting system that provides users with both financial and non-financial information. Budgets, a tool often used, have been around for a long time.
\end{abstract}

Key words: International Control, Budget, operational data, Ministry of Finance in Albania and Kosovo, Empirical Study Accounting Empirical studies, interest, risk, Accountings politics, 


\section{JEL Classification Security System: N0, N1, N2, N3, O1, O2, 03.}

\section{Introduction}

Railway Transportation The other mode that affects tourism is railway transportation. This type of transportation is considered the oldest one. In 19th century the railways were frequently used. Currently in many countries the railways are used for transportation of loads. The reason for this is tourist choice of air or automobile transportation. But there exist such railroads that have been included to touristic packages. For the example, we can give Orient Express railways. But nowadays application of technology and technological innovation gave birth to fast trains which compete with air and automobile transportation modes. (Mudsman P) Internal control is necessary for auditing conducted by independent accountants. Certified public accountants refuse to give opinions about a company's financial statements if there is a lack of internal control. For example, internal control involves the separation of tasks, so that the individual that deals with asset control does not even deal with the recording of transactions in the books of accounting. Capital budgeting, however, does not fit well with many businessmen. This is partly due to the difficulties of preparing a capital budget. Cash flow assessments should be further delayed in the future and unfamiliar terms such as cost weighted average capital and internal rates of return, creep into terminology. Recent years academic studies have focused on emotions to explain the behavior of investors and the performance of financial markets. It should be noted that "Traditional finance theory" is built on the assumption thatinvestorsalwaysmakerationaldecisionshaving asingle objective, maximizing thebenefitinarisk environment and insecurity. The application of financial models means that individuals include information in the decision-making process using probability rules and statistics in calculations, leaving aside emotions. However, it should be noted that investors experience a series of emotions as they make a decision, and the more important this decision is, the stronger the emotions. Calculations related to these terms are often unrecognizable; many businesses have learned to operate without a formal capital budget.

However, properly used, a capital budgeting process can help reduce the risk of making the wrong decision.

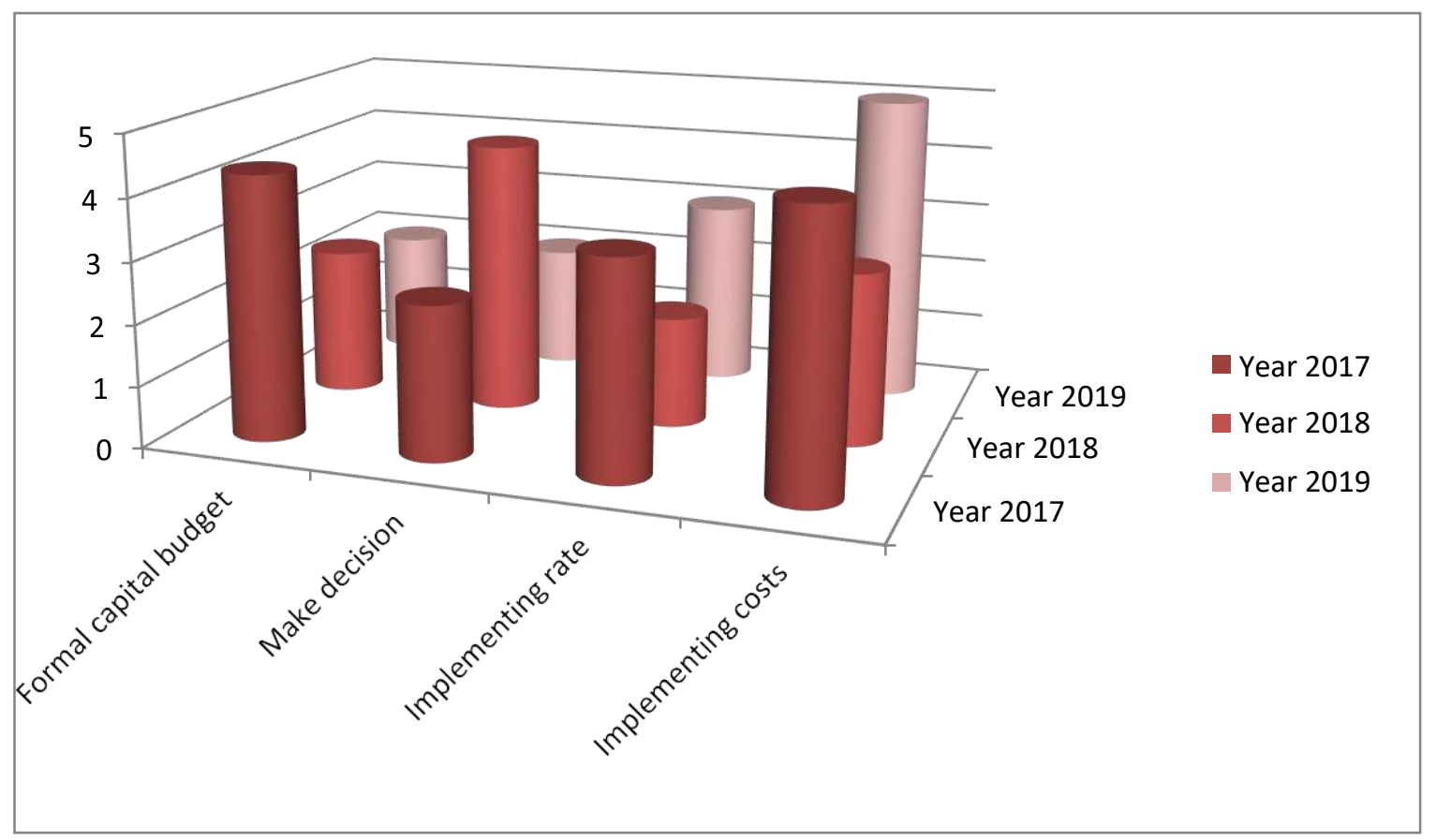




\section{Methodology}

The importance of developing an effective internal control system is not exaggerated. Additional efforts may be required to enforce internal control in a small company, where business procedures are informal and partitioning of tasks is difficult due to the limited number of employees. Even under such conditions, these checks must be carried out. Accountants can help solve problems that arise from lack of internal control. The Scientific research work will become more accessible and easier if it is based on the relevant built-in and verified methodology. The methodology that will be used during the drafting of the paper will be based mainly on the domestic and foreign doctrinal points of view. Not only is this a lost opportunity for investors to benefit from precious stocks in the market, but market exit at its low points hurt investors when they "sell less" and see no returns on their investments.

\section{The negative and positive emotion.}

Business liquidity is determined by the ability of the firm to repay debts and matured liabilities. We can answer this question in two ways:

Economic analyzes that have dealt with rational economic behavior have largely disregarded the role of emotions regardless of research on emotions, the description of the term "emotion" is defined very rarely. This paper upon the characteristics and features it carries is based only on the qualitative method of analyzing the issues addressed in it. It aims to answer the questions: How? Why? What's the way?

\section{Decision making process and importance of Constancy}

The answer is based on the calculation of the operating return on investment, which is measured by dividing the firm's operating income (profit before interest and taxes) with the total invested capital or total assets. In the traditional literacy and decision-making literature of a decision is mainly treated as a cognitive phenomenon and conceptualized as a goal or final point for a more complex process of reflection, which includes an assessment of the consequences and uncertainties. (Parkin 1996) determined the variables of a personal decision-making process consisting of five phases: Defining the Problem; thinking; trial; decision; and action. Parkin identified the impacts commonly affecting this process, such as behavioral history, beliefs, and situations. With all the research done today that includes emotions and choices, it is difficult to ignore the fact that emotion drives decision-making

\section{Literature Review and Hypothesis}

Researcher and Professor Svenson (1996) distinguished four levels of decision-making. The first level of decisionmaking processes involves many quick and mostly automatic and unconscious decisions. The decisions taken with respect to one or more attributes that favor the elected candidate belong to the decisions second level. The third level means that decision-making is a process that refers to choices between alternatives in relation to conflict of intent.

People can believe that their knowledge is more accurate than what they really are, may think that their skills are above the average can have an illusion of control or may be too optimistic about the future. Thus, aspects of others are taken into account when making decisions in uncertainty and people are more affected by perceived risk than objective risk (Diacon \& Ennew, 2001). Risk perception is an indispensable component of financial decision making and other risk-taking behaviors It is also necessary to make a distinction between risk and risk events.

\section{Research goal analyze}

The development of transportation, transportation vehicles, infrastructure and using new technologies in this sector speed up the development of tourism. If we pay attention to the statistics of World Tourism Organization, we may see that the tourism dynamics has changed and increased rapidly between 2005 and 2015.In 2010 international tourist arrivals rose to 940 million. This in turn brought the economies $\$ 980$ billion. This trend can be explained with different factors. But the main important factor here is the rapid development of transportation sector and application of technological innovations which enable the tourists to reach many destinations of the world.

Whether transportation plays important role in enriching the travel experience of a tourist depends on the mode of transportation and the frequency of use. Transportation can turn into a separate tourist attraction element; cruising, Orient Express trains, boat trips along the river and etc. are the best examples to tourist attractions. The effective 
factors in choosing the transportation mode in tourism are given below (Westlake and Robbins 2005, 463): Time limit during tourism studies, as an economic phenomenon, we are starting from the fact that tourists, as consumers of tourist services, travel industry, tourism and other similar activities are found on the one hand.

For example, the English author Likorish (Lickorich) defines the "passenger industry" as part of a national economy that cares for a traveler who visits places outside his country of habitation and permanent employment. The Passenger Industry is a heterogeneous group made up of a large number of trades and industries that have common functions to meet the needs of passengers.

All the stated issues prove the importance of transportation in tourism. As mentioned above the tourist's travel experience starts and ends with transportation. In this sense, if the countries want to gain sustainable development of tourism sector, they must pay attention to transportation sector, reduce monopoly in this sector; provide sound competition opportunities for the companies. This definition is the main basis for the definition of tourism as an economic phenomenon. Through the method of analysis, I intend to analyze the native and international legislation in place for the regulation of legal relations. In psychology, risk is perceived as a subjective construct influenced by the way an event is interpreted. Therefore, perceived risk differently from different people in different contexts. An analysis of how people make investment decisions confirm that objective probability estimates have only a weak impact on the decision-making process. Risk is defined as the probability of decision results in the context of expected service theories, which are applied to understand financial decision making.

Hypothesis: 1: The final evaluation, which was completed by the head of the institution, included the general evaluation with points, the general evaluation in words, proposals for further qualifications based on the evaluations, and also the head of the institution giving ideas of a different leveled job.

Hypothesis: 2: The scales of this evaluation were: especially well, well, enough, not well, inappropriate. On the other side, these elements would serve Albania to create a public administration based on the standards, which our country should have aimed for and realize them for the integration into the European Union.

1. The state role

2. The relationships of the government with community

\section{Conclusion}

Automobile Transportation In short distances automobile transportation comes forward in regard to other modes of transportation. The automobile transportation makes it easy to see local culture and nations. It presents great flexibility in contrast to other modes of transportation (Oter, 2007). The importance of this mode in tourism is also very important. When compared with the prices in air transportation, this mode of transportation is frequently used by tourists because of low prices. But the main factor affecting this choice is time and distance Railway Transportation The other mode that affects tourism is railway transportation. This type of transportation is considered the oldest one. In 19th century the railways were frequently used. Currently in many countries the railways are used for transportation of loads.

The reason for this is tourist choice of air or automobile transportation. But there exist such railroads that have been included to touristic packages. For the example, we can give Orient Express railways. Tourism is considered everywhere as an activity with intense development and high economic prosperity. From the analysis made in the development of tourism in many countries, there are many forms and models of development with its advantages and disadvantages, but which completely crystallize particular policies and programs of running this important economic branch.

Today there is a huge debate about the nature and breadth of the impact that tourism may have on the localities and host societies. Tourism is not only seen as a lucrative activity, but it is acknowledged that the costs and benefits are dedicated to its development. Many researchers have expanded the tourism impact analysis, including in its interior environmental, social and cultural considerations of the importance and intricacies that the tourism development is causing. When tourism impacts are related to its development, their analysis is mainly involved in tourism planning processes. The reason for this can be two-fold: Either the reformers may have implemented the wrong types of reforms or the civil servants may be resistant to reform since they feel that the present system is optimal for them and have created roadblocks for its implementation. 
ISSN 2661-2666 (Online) International Scientific Journal Monte (ISJM) DOI: 10.33807/monte/3/201912499 Volume 3 No. 1 (2020): April

We argue that the one of the possible reasons for this lack of impact might be because the civil service reformers have failed to fully understand the various performance evaluation systems, which in turn means that the system that has been implemented is the wrong one.

We also find that the majority of bureaucrats recognize that the present system is flawed and would be willing to accept a revised system that accurately measures and rewards performance.

In this article we look at the various models of performance management systems and narrow down the performance evaluation system that best fits the context. The evaluation of the performance is determined as an evaluation of the past and actual performance of an administration employee according to the standards organization performance.

The process of evaluation of the performance consists on:

1. The work standards.

2. The evaluation of the actual employee's performance related to these standards 
ISSN 2661-2666 (Online) International Scientific Journal Monte (ISJM) DOI: 10.33807/monte/3/201912499

Volume 3 No. 1 (2020): April

\section{References}

Emmett, Boris, and Jeuck, John C. Catalogues and Counters; A History of Sears, Roebuck \& Co. Chicago: University of Chicago, 1950.

Maslow, A.H. Motivation and Personality. New York: Harper \& Row, 1954.

Mayo, Elton. The Social Problems of an Industrial Civilization. Boston: Harvard Business School, 1945.

Mayo, Elton. The Human Problems of an Industrial Civilization. Boston: Harvard Business School, 1946.

McGregor, Douglas. The Human Side of Enterprise. New York: McGraw-Hill, 1960.

Taylor, F.W. The Principles of Scientific Management. New York: Harper's, 1912, and many editions since.

Wiener, Norbert. The Human Use of Human Beings. Boston: Houghton Mifflin, 1950. Woodward, Joan. Industrial Organization; Theory and Practice. Oxford University Press, 1965.

DCM no. 66, 03.02.2017, "On defining the criteria and the procedures for the establishment of medical university services and structures";

DCM no. 109, 15.02.2017, “On organization and performing of the Agency of Quality Assurance in Higher Education (AQAHE) and Accreditation Board (AB) and defining the fees of quality assurances processes in higher education";

DCM no. 329, 12.04.2017, “On the position and preferential treatment of the academic staff”;

DCM no. 370, 26.04.2017, "On the organization and performing of the high professional college"; 


\title{
AN INVESTIGATION OVER POPULATION INCREASE IN URBAN AREAS AND EMPLOYMENT PROSPECTS IN ALBANIA
}

\author{
Mario Çurçija ${ }^{1}$ \\ Emirjeta Bejleri ${ }^{2}$ \\ ${ }^{1}$ Faculty of Economy \\ University of Shkoder, Albania \\ mario.curcija@unishk.edu.al \\ ${ }^{2}$ Faculty of Economy \\ University of Shkoder, Albania \\ emirjeta.bejleri@unishk.edu.al
}

\begin{abstract}
Migratory movements as individual or collective relocation from a place of origin to a place of destination represent a milestone in a person's life because it implies withdraw from two important places in a person's life: residence and work.

The phenomenon of migration affects demographics of the areas involve: shrinking populations in areas of origin and increasing in destination areas. Given that the causes of migration may be different, in this paper we focus on factors related to job opportunity as determinants of the decision to migrate. In this paper, our aim is to evaluate the relationship between the number of the population residents in a district and the job opportunities in that district in Albania. To perform this analysis, we use quantitative methods: the logit and the multinomial logit regression models based on a dataset of labor force survey for the period 2007-2013 in Albania. In this research we found a positive correlation between the increase in the number of residents in a district and job opportunities in activities different from agriculture, and, in particular the positive effect on job opportunities is higher than the average for women who have attained general education secondary school.
\end{abstract}

Keywords: job opportunities, demographic trend, transitional economies, Albania

JEL Classification: J10, J20, J61,

\section{Introduction}

Job opportunities are a major cause in internal migration. The process of Albania's political transition from a communist system with a centralized economy toward a market economy system, among other things, led to the deindustrialization and restructuring of the economy, which in turn led to a shift of the labor force from the secondary to tertiary sector of services. Such political and economic changes were followed by demographic changes. Unemployment is high in Albania, but it is unevenly distributed in the territory, given that internal areas suffer from economic depression, lack of job opportunities and higher unemployment than western areas, therefore emigration and the consequent depopulation is more pronounced in these areas. 


\section{Literature review}

According to a Marxist view, the city develops as an instrument of the industrial process. But while the quota of the surplus value that is created and realized by the industrial sector starts to decrease, the part of the surplus value created and realized in the city by the second circuit of capital, produced by estate speculation, increases and supersedes the first circuit of capital (Lefebrve, 1974). This causes that the wealth concentrated in a specific urban space determines the creation of a series of relationships that focus the attention of economic operators towards the city.

According to spatial analysis, the explanation for the development and growth of cities in the globalization era is based on the network paradigm (Pain, Van Hamme, Vinciguerra, \& David, 2016) in the sense that in our time globalization requires a great deal of integration and fast communication and participation. The participation of the city in the connectivity networks determines the economic success of the city. The most successful cities and areas are connected and integrated cities in the global economy, because the key activities of capitalism - high levels of innovation and technology - are realizes exactly in globalized urban centers (Scott, 2001). Strategic advantages, dissemination of information, knowledge and know-how, ease of communication and transportation favor the concentration of firms' businesses into one economic cluster (Porter, 1995), (Porter, Clusters and the New Economics of Competitiveness, 1998). Globalization goes along with and the centralization of strategic functions and global cities have comparative advantages for being at the center of the agglomeration of functions process (Sassen, 1994) (Sassen, The Global City: New York, London, Tokyo, 1991).

Cities and areas that, for one reason or another, possess a competitive advantage over other cities, in the freemarket system tend to increase the distance and deepen the advantage, because a small advantage attracts new businesses which in turn enlarge the market dimension, and, vice versa by increasing the demand which, according to Keynesian logic, leads to the growth of supply and the attraction of other new businesses in what (Myrdal, 1957) calls circular causation. The same circular causation may have the opposite effect as a vicious circle. It happens when the withdrawal of the state from some public services leads to a deterioration of the quality of life and therefore the residents that seek for better living conditions so decide to leave, but then this population shrink itself does not justify the presence of some other public services which are further reduced by dragging the system in a kind of vicious circle.

Production tends to focus where there is a broad market, but on the other hand, according to a Keynesian description of multiplicative effects, the market will be wide where the production enterprises will concentrate (Hirschman, 1958) (Arthur, 1989). A large market implies higher productivity and higher specialization and attracts people with knowledge, higher education, skilled professional, i.e., human capital who have better job opportunities and higher incomes (Schultz, 1961) (Becker, 1994). According to (Krugman, 1991) a country itself can differentiate its development into an industrialized "core" because of the advantages in transportation costs, economies of scale, and the share of manufacturing in national income and an agricultural "periphery."

\section{The case of Albania}

Until 1990 free movement in Albania was restricted by the communist regime which aimed at achieving economic self-sufficiency, egalitarianism, erasing inequalities at every level, planning every aspect of economic life including work and residence. The planned urbanization caused that the population growth of major cities during the period 1945 - 1989 was half of the country's population average growth (Kopliku, 2016). The cancellation of the overwhelming boundaries in 1991 caused massive internal migration from hinterland and rural areas towards urban areas.

This transformation is similar to the processes that took place in the western countries during the 1980s. Unlike jobs in the manufacturing sector which can concentrate in both large and small centers, the job opportunities in the service tertiary sector are generally located in urban enclaves where the best talent and creativity are concentrated (Porter E. , 2017). The definition ${ }^{1}$ of "transition" as an intermediate phase of transition from an old equilibrium towards a new equilibrium while conserving some features of the old structures, in the case of former

\footnotetext{
${ }^{1}$ Enciclopedia Italiana di Scienze, Lettere ed Arti - Treccani
} 
communist countries has had a more radical meaning than merely transition; it was as a shock that not merely evolved but had destructive consequences for the production systems (De Mel, McKenzie, \& Woodruff, 2011).

First of all, it is necessary to define the terminology used in this paper: resident population is defined as all persons who reside or intend to reside in the country for at least 12 months, regardless of their nationality ${ }^{2}$. The administrative units, which consist of residential areas used in this work is the district, which in the Republic of Albania is a territorial administrative unit in accordance with Law no. 8652, data. 31.07.2000:

The district is a second-level local government unit; the district represents an administrative-territorial unit, composed of several communes and municipalities with geographical, traditional, economic, social ties and common interests; The district boundaries correspond to the boundaries of the communes and municipalities that comprise it. The district center is located in one of the municipalities included in it. Territorial extension, name and district center are determined by the law. Albania has 12 districts. Their territory is defined by law.

\section{Purpose of the research}

The purpose of this paper is to check the existence of a relationship between the number of residents in an area and the possibilities of finding a job in that area.

Given that in the era of information technology the service sector is pivotal for the economy, we predict that as the service sector thrives in clusters in urban areas then job opportunities will be higher where the resident population is higher.

Another prediction we propose is based on the finding that, since that service sector jobs are largely based on skills, knowledge, high intellectual engagement and less physical performance than in the secondary manufacturing sector, then we expect that the positive effect of the growth of the population resident on job opportunities in an area will be comparatively higher for women with higher education.

\section{Methodology}

In order to test the hypotheses that population growth in an area is associated with increased job opportunities that area, and, in particular women who have achieved a solid formal education, we use two testing methods: logit model and multinomial logit model.

For the first hypothesis we use the logit model that is a regression model where the outcome, the dependent variable is a dichotomous variable which can have only two nominal categories $(1 ; 0)$, while the dependent variable is a continuous variable. In order to define the logit model, we use the cumulative distribution function of a standard normal random variable (Greene, 2011)

$$
\operatorname{Pr}\left(Y_{i t}=1 \mid X_{i t}\right)=\Phi\left(X_{i t} \beta\right)
$$

where Pr represents the probability that the outcome of interest $Y_{i t}$ (the status of a person resident in the district $i$ at the time $t$ ) is employed $=1$ or unemployed/inactive $=0, \Phi$ the cumulative distribution function of the explanatory variable $X_{i t}$, which is the population resident in the district $i$ at the time $t$ where $\mathrm{i}=$ (district of Berat, Dibër, Durrës, Elbasan, Fier, Gjirokastër, Korçë, Kukës, Lezhë, Shkodër, Tiranë, Vlorë) in the year $t=(2007$, 2008, 2009, 2010, 2011, 2012, 2013) $)^{3}$.

So, if the probability is higher than $50 \%$ than we assume that $Y_{i t}=1$ and if the model predicts significantly correctly, meaning that the percentage of correctly predicted responses is significantly higher than $60 \%-65 \%$,

\footnotetext{
${ }^{2}$ Instat Albania | Popullsia

${ }^{3}$ Source: Instat Albania | Popullsia
} 
ISSN 2661-2666 (Online) International Scientific Journal Monte (ISJM) DOI: 10.33807/monte.202004669 Volume 3 No. 1 (2020): April

than we may consider the model as valid. As long as the model is valid, then we can consider the average marginal effect of the explanatory variable on the probability that the outcome of interest is $1=$ employed.

Our sources of information are the quarterly labor force survey (LFS) for the period 2007-2013 in Albania ${ }^{4}$.

According to LFS, 40\% of the employees work in the agricultural sector (Instat Albania, 2019). Since that agricultural employment in low-income countries mainly takes the form of subsistence agriculture, we decided to exclude from the analysis for the first hypothesis the employees in the agriculture sector; therefore, we will refer to the employees in the non-agricultural private sector.

For the second hypothesis, we use the multinomial logit regression model which is an extension of the logit model where the response variable has more than two categories. One category, usually the most frequent, is designed as the reference, base category and the logit regression measures the probability of membership in other categories compared to the probability of membership in the base category depending on changes in the dependent variable. In our case the categories are: 1 - Employed No school, 2 - Employed Primary school, 3 - Employed school classes V-IX, 4 - Employed Upper secondary - vocational 2-3 years, 5 - Employed Upper secondary vocational 4-5 years, 6 - Employed Upper Secondary - general, 7 - Employed Tertiary / University, 8 - Employed Post university / Master resident in the district $i$ at the time $t$. The explanatory variable $X_{i t}$ is the population resident in the district $i$ at the time $t$.

\section{Analysis and Results}

The table below provides descriptive statistics for all variables used in the estimations.

Table 1. Summary Statistics H1

\begin{tabular}{cccccc}
\hline Variable & Obs & Mean Std. & Dev. & Min & Max \\
\hline District & 52281 & 6.738815 & 3.811573 & 1 & 12 \\
\hline District_Popul & 52281 & 205.2261 & 177.5034 & 28.3765 & 552.9084 \\
\hline Labour_Status & 52281 & 0.3267726 & 0.4690378 & 0 & 1 \\
\hline
\end{tabular}

Note: The district population in thousand; agriculture sector excluded

Source: own elaborations

The results of the logit test are presented in Table 2. Logit test H1. There was a significant positive correlation (pvalue $<0.01$, coef. $=0.001$ ) between increasing in the population of the district and job opportunities in the nonagricultural private sector. The model is valid as it correctly predicts $67 \%$ of the responses.

Table 2. Logit test $\mathrm{H1}$

\begin{tabular}{ccccccc}
\hline Labour_Status & Coef. & $\begin{array}{l}\text { Std. } \\
\text { Err. }\end{array}$ & $\mathbf{z}$ & $\mathbf{P}>\mathbf{z}$ & {$[\mathbf{9 5 \%}$ Conf. } & Interval] \\
\hline District Popul. & 0.001 & 0.000 & 15.770 & 0.000 & 0.001 & 0.001 \\
\hline _cons & -0.893 & 0.014 & -61.840 & 0.000 & -0.922 & -0.865 \\
\hline
\end{tabular}

\footnotetext{
${ }^{4}$ Source: Instat Albania | Labor Market. Micro data
} 
ISSN 2661-2666 (Online) International Scientific Journal Monte (ISJM) DOI: 10.33807/monte.202004669 Volume 3 No. 1 (2020): April

As far as the model is valid, then we can measure the average marginal effect (Table 3. Average marginal effect). In this case, the average marginal effect of the district's population increases by 1,000 units on the probability of the status "employed" in the non-agricultural private sector is $+0.02 \%$.

Table 3. Average marginal effect

\begin{tabular}{lcccccc}
\hline \multicolumn{3}{c}{ Delta-method } & & & & \\
& dy/dx & Std. Err. & $\mathbf{z}$ & $\mathbf{P}>\mathbf{z}$ & $\begin{array}{c}{[\mathbf{9 5 \%}} \\
\text { Conf. }\end{array}$ & Interval $]$ \\
& & & & & & \\
\hline District Popul. & 0.0002 & 0.0000 & 15.9100 & 0.0000 & 0.0002 & 0.0002 \\
\hline
\end{tabular}

The table below shows summary statistics for the multinomial logit tests by educational level grouped by gender.

Table 4. multinomial logit and average marginal effect by gender

\begin{tabular}{|c|c|c|c|c|c|}
\hline Gender & Edu. Level & Coef. Std. Err. & $\mathbf{P}>\mathbf{Z}$ & $\mathrm{dy} / \mathrm{dx}$ & $\mathbf{P}>\mathbf{Z}$ \\
\hline Male & 1- No school & $.0004019 \quad 0004357$ & 0.356 & -0.00000182 & 0.571 \\
\hline Female & 1- No school & $-.0013532 \quad .0006017$ & 0.025 & -0.0000164 & 0 \\
\hline Male & 2 - Primary & $.0002912 \quad .00019$ & 0.125 & -0.0000164 & 0.044 \\
\hline Female & 2 - Primary & $.0003436 \quad .0002036$ & 0.091 & -0.0000155 & 0.101 \\
\hline Male & 3 - 8/9-years school & (base outcome) & & -0.00029 & -0.0000159 \\
\hline Female & 3 - 8/9-years school & (base outcome) & & -0.00035 & -0.000294 \\
\hline Male & 4 - Up. Sec. Vocation 2-3 yrs & .0011822 .0001881 & 0 & -0.000354 & 0.002 \\
\hline Female & 4 - Up. Sec. Vocation 2-3 yrs & .0011586 .0002963 & 0 & 0.0000198 & 0.077 \\
\hline Male & 4 - Up. Sec. Vocation 4-5 yrs & $.0010869 \quad 0001065$ & 0 & 0.00000968 & 0 \\
\hline Female & 4-Up. Sec. Vocation 4-5 yrs & .0008829 .0001433 & 0 & 0.0000668 & 0.059 \\
\hline Male & 6 - Upper Second. - general & $.0010184 \quad .0000962$ & 0 & 0.0000238 & 0 \\
\hline Female & 6 - Upper Second. - general & $.0015568 \quad .0001134$ & 0 & 0.0000777 & 0 \\
\hline Male & 7 - Tertiary / University & $.0022542 \quad .0001267$ & 0 & 0.0001494 & 0 \\
\hline Female & 7 - Tertiary / University & $.0024771 \quad .0001332$ & 0 & 0.0001231 & 0 \\
\hline
\end{tabular}


ISSN 2661-2666 (Online) International Scientific Journal Monte (ISJM) DOI: 10.33807/monte.202004669 Volume 3 No. 1 (2020): April

\begin{tabular}{llllllll} 
Male & 8 - Post university / Master & .0019608 & .0007004 & 0.005 & 0.0001615 & 0.051 \\
\hline Female & 8 - Post university / Master & .0030982 & .000668 & 0 & 0.00000273 & 0 \\
\hline
\end{tabular}

The base category of the employed by educational level, i.e., the largest category, are the employed who have attained the 8/9-years school education level.

The effect of district population increase does not appear to have a significant effect (pvalue> 5\%) on the employed persons that have attained only primary school or no school at all.

Higher formal education increases the probability of job opportunities for people who have attained a higher education level than 8/9-years school; the more the district's population increases, the lower is the percentage of the employees who have attained only 8/9-years of education.

The district's population increase of 1,000 units has a negative marginal effect on the employment of people with an 8/9-year school education level; for women the negative marginal effect is higher $(-0.04 \%)$ than for men ($0.03 \%)$. Also, population growth has a higher effect in amplitude for women, this time a positive effect, for women who have attained upper secondary general education: for women it is $+0.008 \%$ while for men it is four times lower, $+0.002 \%$.

For the other educational levels, the marginal effect of population growth is higher for men than for women.

\section{Discussion}

Statistical analyzes confirm our expectations that population growth is associated with increased opportunities to find a job in the non-agricultural private sector. If this population growth is the effect of another cause such as proximity to markets, greater openness of urban areas to globalization, better geographical location, these are considerations that are not the object of study of this paper and may be evaluated as a topic in the future. Population growth appears to have a higher positive effect on women who have attained upper secondary general education than men who have attained the same education level.

Increasing job opportunities, on the other hand, also increase the population of the district, as we can easily imagine situations where people migrating toward a certain district tend to take with them their families. Also, districts where job opportunities are higher tending to attract the unemployed from economically depressed areas. In this case, the decline of unemployment in economically depressed areas is not the result of an increase of job opportunities but rather of job-seekers abandonment. Therefore, in interpreting the results we are careful not to present the relation of the number of resident populations - job opportunities as a unidirectional relationship, but as a dual process. 
ISSN 2661-2666 (Online) International Scientific Journal Monte (ISJM) DOI: 10.33807/monte.202004669 Volume 3 No. 1 (2020): April

\section{References}

Arthur, W. B. (1989). Competing Technologies, Increasing Returns, and Lock-In by Historical Events. The Economic Journal, Vol. 99, No. 394, 116-131.

Becker, G. (1994). Human Capital: A Theoretical and Empirical Analysis With Special Reference to Education. Chicago: The University of Chicago Press.

De Mel, S., McKenzie, D., \& Woodruff, C. (2011). Enterprise Recovery Following Natural. The Economic Journal, 64-91.

Greene, W. (2011). Econometric Analysis. New Jersey: Prentice Hall.

Hirschman, A. O. (1958). The Strategy of Economic Development. New Haven: Yale University Press.

Instat Albania. (2019, 12 12). Të dhëna administrative të tregut të punës. Tratto il giorno 01 12, 2020 da Instat Albania: http://www.instat.gov.al/al/temat/tregu-i-punës-dhe-arsimi/të-dhëna-administrative-të-treguttë-punës/\#tab2

Instituti i Statistikave . (2014). Nje klasifikim i ri urban-rural i popullsise shqiptare. Tirane: Pegi.

Kopliku, B. (2016). Migrimi i Brendshem ne Rajonin e Shkodres gjate viteve 1945 - 1990. Buletini Shkencor Universiteti i Shkodres, Seria Shkencat Shoqerore.

Krugman, P. (1991). Increasing Returns and Economic Geography. Journal of Political Economy,

Lefebrve, H. (1974). La production de l'espace. Paris: Éditions Anthropos.

Lefebvre, H. (2018). La produzione dello spazio. Pgreco.

Myrdal, G. (1957). Economic theory and under-developed regions. London: Duckworth.

Open Data Albania. (2013). Popullsia sipas qarqeve, densiteti dhe urbanizimi 2001-2013. Tratto il giorno 0110 , 2020 da open.data.al: http://open.data.al/sq/lajme/lajm/lang/sq/id/716/Popullsia-sipas-qarqeve-densiteti-dhe-urbanizimi-2001-2013

Pain, K., Van Hamme, G., Vinciguerra, S., \& David, Q. (2016). Global networks, cities and economic performance: Observations from an analysis of cities in Europe and the US. Urban Studies, 53 (6), $1137-1161$.

Petrakos, G. C. (1997). Industrial Structure and Change in the European Union: Comparative Analysis and Implications for Transition Economies. Eastern European Economics, 41-63.

Popescu, C. (2014). Deindustralization and Urban Shkrinkage in Romania. What lessons for the spatial policy? Transylvanian Review of Administrative Sciences, 42, 181-202.

Porter, E. (2017, October 10). Why Big Cities Thrive, and Smaller Ones Are Being Left Behind. Tratto il giorno January 06, 2020 da New York Times: https://www.nytimes.com/2017/10/10/business/economy/bigcities.html

Porter, M. (1995). Clusters and the New Economics of Competitiveness. Harvard Business Review, 77-90.

Porter, M. (1995). The Competitive Advantage of the Inner City. Harvard Business Review, MayJune,, 53-71.

Porter, M. (1998). Clusters and the New Economics of Competitiveness. Harvard Business Review, 
ISSN 2661-2666 (Online) International Scientific Journal Monte (ISJM) DOI: 10.33807/monte.202004669 Volume 3 No. 1 (2020): April

Sassen, S. (1991). The Global City: New York, London, Tokyo. Princeton NJ: Princeton University Sassen, S. (1994). Cities in a World Economy. London : Pine Forge Press.

Schultz, T. W. (1961). Investment in Human Capital. The American Economic Review, 51(1), 1-17.

Scott, A. J. (2001). Globalization and the rise of city- regions. European Planning Studies, 9(7), 813-826. 


\title{
TOURISM INDUSTRY OF THE WESTERN BALKAN COUNTRIES BETWEEN EXISTING RESOURCES AND REGULATION OF THE EUROPEAN UNION
}

\author{
Academician.Prof.Dr.Slobodan Nešković \\ University Business Academy Novi Sad, Serbia, \\ slobneskovic@gmail.com
}

\begin{abstract}
The aim of the current research is to scientifically consider the existing potentials of the tourism industry of the Western Balkan countries in their efforts to eliminate the manifested anomalies and join the European Union. The achieved results, recommendations and profiled conclusions will benefit the relevant state actors in the concept of tourism promotion and European integration. It is necessary to determine the legal regulations of the European Union in the field of tourism based on the Resolution of the United Nations General Assembly 39/248, the Law on Consumer Protection, the Law on Environmental Protection and other legal documents. The Western Balkans subregion consists of countries that are in one of the established phases of the European integration process, for which tourism is a significant economic branch. The starting hypothesis is that the tourism industry of the Western Balkans with existing resources and the implementation of European Union regulations represents an objective chance for overall social development, ie integration into the community of developed countries. By applying the methodological procedures of analysis of available materials, synthesis, description and comparison, we will consider the essential postulates of our topic. The focus of the study is the EU legal regulations relating to the tourism of the observed countries and the specifics of the resources of this industry, important for their economic and overall social development. For all these countries, tourism, modified according to modern trends, potentially means a first-class economic branch and a great chance for the prosperity of communities. The institutions of the European Union have conceived specific legal legislation in this area, as special regulations that are binding on members and countries in certain stages of accession. The initial document adopted by the EU is the Council Directive 90/314 of 1990 on package arrangements. It consists of ten members who fully protect the consumer regardless of the position in the contract. Then, Regulation EC 261/2004 related to air transport issues. It provides for the rights of passengers in air traffic with specific conditions and amounts of compensation that airlines pay to damaged passengers. The well-known standards ISO 9001, ISO 14001 and ISO 22000 HACCP specific to the field of tourism are also applied. Our article treats the peculiarities of the tourist resources of the Western Balkan countries as a whole, by considering the positive and negative aspects. The advantages of the physical - geographical and traffic position of Montenegro, Serbia, Macedonia, Albania and Bosnia and Herzegovina, the diversity of natural resources, healthy living environment, cultural treasures, ethnographic elements, conditions for foreign investment and international cooperation are taken into account. Aggravating factors are reflected in political contradictions, unfavorable infrastructure, economic crisis, lack of professional staff, insufficient legal regulations and inadequate attitude of the authorities. We believe that the leading state entities must eliminate the weaknesses of the legal system and incorporate the legal legislation of developed countries and the European Union itself into their own legislation. It is necessary for the state leaders to pay more attention to the planned investments in tourism, hotel industry and processing industry. Implement the funds of the pre-accession funds of the European Union in fruitful development projects. Use the favorable geographical position with transport networks, diverse natural resources and a healthy environment to promote the tourist economy with accompanying activities. Numerous cultural and historical values and specific ethnographic contents contribute to the overall ambience. Affirm paradigms that motivate foreign investors, where business strategies are formulated based on established international principles. New initiatives for cross-border cooperation between the countries of the Western Balkans are supported by the institutions of the European Union and the United States, especially in order to eliminate mutual problems and strengthen economic capacities.

Keywords: tourism industry, regulations, resources, Western Balkans, European Union
\end{abstract}

\section{Introduction}

The Western Balkans region is a broader term than a geographical area called the Balkan Peninsula. The Western Balkans most commonly refers to the seven countries Bulgaria, Albania, Macedonia, Romania, Serbia, Montenegro, Bosnia and Herzegovina, and less frequently Croatia, Slovenia, Moldova, Greece and the European part of Turkey. Due to its turbulent past, the Western Balkans is today a mix of different cultures, with four major religious communities operating in its territory: Islam, Orthodoxy, Catholicism and Judaism. 
The first civilizations that shaped the world today were created in this area. The shores of the Western Balkans are flooded by the waters of six warm seas: the Adriatic, Ionian, Aegean, Mediterranean, Marble and Black Seas. The continental part is dominated by the high mountain ranges of the Dinaric mountains, the Balkans and the Carpathians, the northern part of the Western Balkans flows through large rivers such as the Danube, the Sava and the Tisza, while in the interior there are numerous spas and springs of hot and cold mineral waters. Due to the economic underdevelopment of most Western Balkan countries, the area is largely preserved in its pristine nature as well as clean and comfortable air. Large forest areas and various herbs still cover large parts of the Western Balkans. This space represents the shortest link between Europe and Asia, whether by road, river or air. Due to all these natural features, the Western Balkans region stands out from the rest of the world and represents a great potential for the development of many industries, especially tourism. As the region of the Western Balkans is naturally divided into coastal and continental parts, tourism in these areas has not developed equally. Tourism is far more developed in the areas and countries that own the sea than in the continental regions, but the coastal areas are inferior to the world tourist destinations. Some parts of the Western Balkans have been in the swing of tourism in recent years, while most countries in the region are still in an unenviable position relative to the same or similar parts of Europe and the world.

However, as tourism as an industry is in constant development when it comes to world frames and as the number of tourists visiting various tourist destinations is increasing steadily from year to year, it opens the possibility for the Western Balkans region to be actively involved in the development of this promising industry. To make progress in the field of tourism, which can undoubtedly bring a lot of revenue to the Western Balkan countries, it is necessary to take this important issue more seriously and to develop a regional strategy for tourism development in this part of Europe.

\section{Materials and Methods}

The European Union, as a supranational community of twenty-seven European states, has modern and advanced laws governing all areas essential to the functioning of such a creation. European Union laws are considered the most liberal and up-to-date laws in the world.

The European Union regulates tourism through numerous laws. Consumer laws and the Environmental Protection Act, which is also one of the most important laws of the European Union, should be mentioned as significant laws. (Neskovic, S., Djelic, T. A., Antonovic, R., Lutovac, M. \& Ketin, S., 2020, p. 4063)

The European Union's tourism regulations are largely based on UN General Assembly resolution 39/248 on consumer protection. The 1997 Treaty of Amsterdam renumbered the Treaty establishing the European Union, which states in Article 153 that consumer rights are based on five fundamental rights, namely:

- protection of health and safety of consumers,

- protection of consumers' economic interests,

- consumer's right to information and education,

- the right to compensation and

- association, representation and participation of consumers to exercise their rights.

Thanks to the expansion of tourism as an industry, the Council of the European Union decided to declare 1990 as the "European Year of Tourism". In this regard, several standards are being introduced in the European Union to regulate this perspective area. Among the most important documents adopted by the European Union are EEC Council Directive 90/314, which was adopted on 13.06.1990. and relating to the package deal and Regulation 295/91, which was later replaced by EC Regulation 261/2004 relating to air transport.

The directive further regulates the details regarding the price change, the deadline by which the prices may change and the characteristic cases when the organizer is not obliged to comply with the indications from the brochure. Also, according to this Directive, the organizer is obliged to inform the consumer about any changes 
before the trip, which can, without any consequences, cancel the arrangement or accept another arrangement. Neskovic, 2013, p. 18)

What is still important to say about this Directive is that the consumer is obliged to report as soon as possible any irregularities which deviate from the rules laid down in this Directive.

The regulation regulates the rights of passengers in air traffic and determines the amount of compensation the airline is obliged to pay to the injured passenger. As it often happens that an airline receives more bookings than the number of passengers that can objectively be carried (overbooking), the aforementioned Regulation has been enacted, which protects passengers' rights and provides them with the payment of adequate financial compensation. The basic change to Regulation 295/91 relates to a nominal increase in the amount that an airline is obliged to pay to an injured consumer (passenger). Also, this Regulation stipulates that airlines are not obliged to pay the consumer compensation only if the flight is canceled or there is a delay in case of emergency, which implies bad weather, political instability, strikes, security risks, technical problems on the plane. unexpected problems that may affect flight safety.

Also, the European Union has adopted several standards that must be respected in the territory of the European Union. Among the most significant standards adopted by the European Union, which are directly related to tourism, are:

- ISO 9001 related to quality management,

- ISO 14001 relating to environmental protection and

- ISO 22000 HACCP related to food safety.

The implementation of these standards in the Western Balkan countries is of great importance as these standards serve as a precondition for the development of tourism in this region.

In most cases, the Western Balkan countries have aligned their laws and standards with those of the European Union.

Tourism in the European Union accounts for 4\% of GDP, all because the European Union seeks to create a common tourism market through coordination of local, regional and national interests. In this regard, the European Union has developed different methods to accelerate the development of tourism through the investment of private and state capital in this industry. For decades, the European Union has been paying close attention to tourism development. For this reason, the European Union has adopted and implemented several major projects related to the development of this industry. The first such project was adopted in the 1980s and was called the "Tourism Sector-Horizon 92", and related to tourism planning and development in the European Union. In the 1990s, the Green Paper project was adopted, which refers to the development of rural, cultural and social tourism, the promotion of tourism-related education and the protection of the environment and cultural heritage. In the late 1990s, the European Union adopted a multi-year program to promote tourism (Philoxenia), covering the period 1997-2000. years. This program aimed to improve the quality and competitiveness of European tourism in the international market. The European Union stresses in particular that tourism development policy should be implemented with other international organizations such as the World Tourism Organization, the International Bureau of Social Tourism, etc.

The construction of tourist and related facilities in the European Union is provided within existing institutions through the following financial elements (Neskovic, Ketin, Secerov \& Djelic, 2018, p. 45):

- Assigned financial assistance through a cohesion fund serving the development of underdeveloped countries of the European Union, a regional fund serving the development of individual regions of the European Union, a social fund through which various social programs related to tourism and an agricultural fund earmarked for rural tourism development, especially in mountain areas of the European Union.

- Special-purpose loans provided by the European Investment Bank and the European Coal and Steel Community. 
ISSN 2661-2666 (Online) International Scientific Journal Monte (ISJM) DOI:10.33807/monte.202004673 Volume 3 No. 1 (2020): April

- State aid in the tourism sector where investments are made in hotels, recreation centers, infrastructure and more, which indirectly affects tourism development.

- New forms of intervention aimed at attracting significant funds for tourism, related to stimulating tourism development, improving services, improving transport and infrastructure, etc.

As transport is considered an inseparable part of tourism as an industry, the European Union in this regard allocates significant funds for the promotion of all forms of transport and seeks to establish a single transport market throughout the European Union.

To help and meet the specific needs of countries in the Adriatic area (Italy, Slovenia, Croatia, Bosnia and Herzegovina, Montenegro, Albania, Greece and Serbia), the European Union has adopted a program called IPA Adriatica. This program has been created through a series of meetings and at the initiative of the European Commission and involves financial assistance to these countries through the territory, environment, population, migration, economy, labor market, trade, tourism, infrastructure and transport and research and innovation.

By the IPA Implementing Regulation, the broad assistance objectives are as follows:

- Promoting sustainable economic and social development in the border area;

- We work together in areas such as the environment, natural and cultural heritage, public health and the prevention and fight against organized crime;

- Ensuring effective and secure borders;

- Promoting joint smaller actions involving local actors from border areas.

Based on its criteria, the World Tourism Organization (UNWTO) divides tourism into eight basic parts, namely:

- Domestic tourism - means tourist travels of the domestic population (residents) to tourist destinations within the country of origin. This type of tourism is also one of the most massive forms of tourism in the world;

- Receptive tourism - means non-resident tourists staying in the observed country;

- Exotic tourism - refers to the travel of a resident's resident country to a tourist destination of another country;

- Internal tourism - refers to a combination of domestic and receptive tourism;

- National tourism - means all tourist travels of residents of a particular country inside the country of origin and abroad;

- International tourism - refers to a combination of receptive and broadcast tourism;

- Intra-regional tourism - refers to all tourist trips of residents of one country of a certain region to destinations in other countries of the same region (example: tourist trip of citizens of Serbia located in Europe to another country from the European continent) and

- Interregional tourism - refers to the tourist travels of residents of one country to another country that does not belong to the same region to which the country of origin belongs (example: trips of residents of Serbia belonging to the European continent to a country located on an African or another continent). 


\section{Results}

Due to the increasing tourist offer in the world and the special needs of tourists, there is a need to modernize the tourist offer. Contemporary trends in tourism development imply constant innovation in this field. Today's tourist is very picky and not satisfied with a classic offer such as staying in one place. The modern tourist offer has to offer numerous offers in terms of day or day trips to nearby tourist destinations. This type of entertainment for tourists also entails additional income for tourism organizations. In addition to the excursion, the demanding tourist is looking for a good tourist guide, which will provide him with the necessary pleasure. Travel guides and other tourism staff (staff in hotels, restaurants, various hosts in private accommodation and ethno-households) are of great importance in modern tourist offer. Consequently, there is a need for additional education and training of human resources for tourism purposes. Only well-educated and educated tourism workers can provide tourists with the necessary satisfaction and contribute to the tourist's return in the coming period. (Neskovic \& Jovanovic, 2016, p. 51.)

It has long been a common opinion that quality is the best advertisement. However, without tourism marketing in the contemporary environment, it is unlikely that any destination will be visible on the tourist map of the world. The modern type of tourism business involves "strong" marketing. Tourism fairs are the best form of tourism marketing in the world as well as in this part of Europe. One of the biggest tourism fairs in this part of Europe is certainly the Belgrade Fair, which is held every year in the Serbian capital. In addition to this important way of promoting tourism and tourism offers, internet marketing is becoming more and more prevalent. The Internet, as a global electronic network, is growing rapidly and has an increasing number of users. Good internet promotion can increase the number of tourists, and therefore the earnings of tourist workers and the entire economy of this region. Travel managers also use other forms of marketing, such as filming and broadcasting various tourist spots, printing publications and flyers, etc. which help develop tourism and generate profits. To develop tourism in the modern environment, various conferences, seminars, congresses and scientific meetings are increasingly organized, aimed at educating the professional public in the field of tourism, but also in the best way to guide the development of this profitable industry. These gatherings are usually international, so that tourism potentials are best presented to potential foreign tourists and investors.

As the number of new tourist destinations in the world tends to increase, while traditional tourist destinations are declining, so is the opportunity to see tourism in the post-socialist and transitional countries in the postsocialist and transitional countries as a promising economic branch develops and reaches the level of development as in the countries of western and southern Europe.

The countries of the Western Balkans have characteristics that do not undoubtedly correspond to contemporary tourist trends in the world, which is primarily concerned with:

- good physical-geographical and traffic position;

- diversity of natural resources;

- favorable climate characteristics;

- healthy environment;

- cultural and historical treasure;

- specific ethnographic elements;

- favorable economic conditions for foreign investors;

- a large initiative space with a large population;

- interstate cooperation through various agreements and special links between Serbia and Bosnia and Herzegovina. 
An analysis conducted by the World Tourism Organization (WTO) showed that tourism segments such as marine, sports, health, urban, cultural, congress and rural tourism will see the highest growth in tourist traffic in the coming period. Analyzing the facts and current trends in tourism development, it is concluded that the Western Balkans have all the necessary characteristics for the development of a profitable industry such as tourism. Also, these countries represent a great unknown for world tourists, so the adventurous spirit of world tourists can contribute to the development of tourism in the Western Balkans.

In addition to these advantages of the Western Balkans, there are many impeding factors for tourism development in the region, such as unstable political situation, poor regulation, lack of staff, poor infrastructure, lack of adequate cross-border cooperation, poor payment ability of the local population, traditional aversion and fear of the developed countries of Europe towards this region, insufficient interest of the authorities and lack of strategy for tourism development in this region, aging of the population, poor overall demographic picture, migration of educated and working population towards the countries of Western Europe and developed countries of the world, etc.

\section{Discussions}

The countries of the central part of the Balkan Peninsula (Serbia, Macedonia, Bosnia and Herzegovina and Albania) have enormous potential for tourism development. These countries contain the natural and social resources necessary for the development of this industry, but the development of tourism in these countries does not closely follow the upward trend in the European Union and other Western Balkan countries. Practically, in these countries there is a great disparity between the potential and resources on the one hand and the number of tourists and the profit generated on the other. Taken as a whole, the countries of the central part of the Western Balkans (Serbia, Macedonia, Bosnia and Herzegovina and Albania) have an excellent physical, geographical and traffic position.

Two of the four countries (Bosnia and Herzegovina and Albania) have access to the warm seas of the Mediterranean (Adriatic and Ionian). Unlike Bosnia and Herzegovina, which goes to the Adriatic Sea only a small part around the town of Neum, which is a potential tourist attraction because it has over 260 sunny days a year and is located next to the Peljesac peninsula, Albania has a large coastline and beautiful sandy beaches. Its coast is flooded by the waters of the Adriatic and Ionian seas and the straits called "Otranska vrata", which connects southern Italy and southwestern Albania. The Albanian coast is intersected by bays, river deltas, and nearby are wetlands that are home to numerous plant and animal species, as well as several interesting cities. The length and beauty of the Albanian coast open up great opportunities for tourism development in this part of the Western Balkans. Albania is currently in high momentum when it comes to sea tourism. This "tourism boom" in Albania is, first and foremost, the result of a good connection with foreign countries. The Albanian diaspora has invested a lot of money in infrastructure construction and alone accounts for over $50 \%$ of the total number of tourists who visit this country annually. On the coast of Albania, diversity of architecture is expressed. In addition to modern hotels, there are still traces of dictatorship architecture in coastal towns, as well as oriental architecture as a result of centuries-old Turkish rule in this region. In the hinterland of the seashore, in one part there is a fertile plain, while the other part of the coast is hidden by high mountains, which is an exceptional tourist attraction for tourists who are adventurous in spirit. A special advantage for the development of maritime tourism in Albania is the ports of Durres, Valona and St. John, located at the mouth of the Drima into the Adriatic Sea.

Although the number of tourists on the coast of Albania is increasing year by year, it is still not enough to speak of a developed industry. The development of sea tourism in Albania is still in its early stages. The development itself is compounded by the many problems facing the Albanian government, such as the lack of quality and modern infrastructure, the impurity of the Albanian coastal cities, and the underdeveloped awareness of the Albanian people about the need to develop tourism in coastal areas. Also, a major problem is the lack of modern legislation in the field of tourism, as in Greece or Turkey, as well as the lack of incentive measures by the Albanian government for the development of maritime tourism.

In addition to the sea, which is a great tourist potential, important central routes connecting Europe to the Asian continent pass through the central part of the Western Balkans. There are also three road corridors passing through this part of Europe and one river European corridor which, in addition to sea tourism, provide these countries with the opportunity to develop many other tourism sectors such as transit, nautical, fishing tourism, etc. and enable safe and unhindered travel of tourists through this region. As modern roads are a prerequisite 
for the development of the economy and therefore tourism, the construction of these roads should be used to enhance the tourist offer of this region, inter alia, through good road marketing.

The Danube, as a large navigable river, opens the door for the development of other attractive tourist branches such as eco and ethno tourism, sports tourism, and near its shore, there are numerous archeological sites, medieval and ancient cities and the largest European gorge "Djerdap". As a navigable river of regional importance, the Sava connects Serbia and Bosnia and Herzegovina and, together with the Danube, represents an exceptional location for the development of nautical and urban tourism. Together with the Danube, the Tisza and their tributaries, the Sava opens the possibility for the development of agro-tourism and agriculture, which is an accompanying tourism branch, because in this way healthy food is obtained, which is one of the basic conditions of the European Union in the field of consumer protection.

A great advantage for the development of tourism in this area is the very dynamic relief. The ground rises abruptly from the Adriatic and Ionian seas and descends over the high mountains into the Pannonian Plain. The central part of the Balkan Peninsula is interspersed with numerous watercourses, valleys, valleys, natural and artificial lakes with diverse flora and fauna. High potential for the development of winter, sports, recreational, health, eco and ethno tourism in these areas is provided by the mountains that abound in this area. These countries are home to famous mountains where this type of tourism has been developed to some extent, and great potentials in the form of high and beautiful mountains, where tourism is still underdeveloped or underdeveloped.

Among the most famous mountain tourist centers in this part of Europe are certainly the mountains around Sarajevo where the 1984 Winter Olympic Games were held. These mountains have modern sports and recreation centers for winter sports.

The mountains of the central part of the Balkan Peninsula are characterized by gentle slopes suitable for winter sports, a continental climate with cold winters and mild summers and beautiful scenery along which clear and fast mountain streams flow. The mountains of Serbia, Bosnia and Herzegovina and Macedonia, in addition to the benefits they offer when it comes to the development of winter tourism, are ideal for health, sports, recreational, eco and ethno tourism, while the high Albanian mountains favor the development of mountaineering as a form of sports, recreational and adventure tourism. Also, these mountains represent the potential for the development of congress tourism, which is increasingly prevalent in the world. There are very few adequate facilities for this type of tourism in the area of this part of the Western Balkans, so investing in this area could bring great economic benefit to these countries.

On most mountains in this part of the Balkan Peninsula, there are well-equipped trails for winter sports. Most of these trails are located in Bosnia and Herzegovina and Serbia, and the last major investment in this field was realized with the help of the Government of Serbia on Stara Planina, which is separated from other Serbian mountains by the amount of snowfall during the year. Nevertheless, the most famous winter tourism center in this part of Europe is certainly Kopaonik. On this mountain there is a modern equipped sports center for winter sports with complete supporting infrastructure and facilities intended for tourists. The growth of foreign guests is recorded on this mountain year after year.

The mountains of northern Albania, western Macedonia and southern Serbia in Kosovo and Metohija have the highest number of snow days in this part of Europe. Except for Brezovica on Šar Planina, these mountains are not sufficiently used for the development of winter sports. The volatile political situation in this part of the region and the dictatorship that has ruled Albania have made tourism in this part of Europe sidelined. In recent years, there has been a strong initiative to develop this industry in these areas.

In addition to winter tourism, the mountains of these countries have exceptional conditions for the development of other forms of tourism. Rich in water and river flows, the mountains of this part of the Western Balkans are a real asset in the form of clean mountain air and healthy food produced on their slopes. Also, these mountains are rich in forests and other wildlife. Due to such characteristics, other forms of tourism such as ethno and ecotourism and gastronomic tourism are increasingly represented on them. Some of these mountains have been declared national parks and protected by the state, which contributes to the conservation of ecology and biodiversity, which are a prerequisite for the development of these tourist branches. (Neskovic, Ketin, Secerov \& Djelic, 2018, p. 47) 
Zlatibor, Tara, Divcibare, Fruska Gora, known for its large number of monasteries, Albania's Tomori Mountain National Park, visited every August by pilgrims, the mountains in Macedonia Jakupica, whose peaks offer a unique view of Thessaloniki and the Aegean Sea, Dinara located on the border of Bosnia and Herzegovina with Croatia, but also Mount Rtanj, which is widely known for its medicinal plants and on the slopes of which grows an endemic herbal species known as Rtanj tea.

In addition to the mountains, this area is also home to numerous plateaus, the most famous being the Pester Plateau. This plateau is known worldwide for the production of the famous hay cheese. In this part of the Western Balkans is located the Deliblatska sandstone as the only one of its kind in this region.

The natural resources of these regions are complemented by numerous river streams, natural and artificial lakes that are abundant in this part of the Balkans. This is the place where the "vein of the houses" of Europe, the Danube, flows. The Danube, the second largest river in Europe, is an invaluable asset as a large number of tourists sail its waters. On the Danube there is the Djerdap National Park which is an exceptional tourist attraction. Many endangered and unique plant and animal species are home to this national park. The banks of the Danube have been inhabited for centuries, and numerous civilizations such as Lepenski Vir and Vinca have arisen in the area, whose archeological excavations make it an extremely attractive location for tourists navigating this great European river. In addition to these prehistoric civilizations, the Danube also abounds in sites dating back to ancient times, and on its shores is the famous Trajan's board, which testifies to the Roman presence in the area and serves as evidence that a very important Roman road connecting Rome with the province passed. Also, fortresses were built on the banks of the Danube in the Middle Ages, which today represent exceptional tourism potential (Petrovaradin, Kalemegdan, Smederevo, Golubac). The French oceanologist Jacques Custo, who explored the waters of the Danube in the 1980s, made a major contribution to the acquisition of ecological awareness and, therefore, to the conservation of biodiversity, which is very important for tourism development.

The most famous spa in this area is certainly Vrnjacka Spa, which is also the seat of the municipality. There are numerous accommodation capacities in Vrnjacka Banja as well as numerous events such as: "Vrnjci Carnival", which gives tourists a special atmosphere. This spa is known for its potential in the world. There are a large number of cultural, historical and religious monuments near Vrnjacka Banja, which contributes to the development of both spa and other forms of tourism.

However, not all spas in this area are in such good condition. As an example of this claim can be cited Kursumlija Spa, which due to negligence, is declining from year to year, so that it remains without inhabitants, infrastructure, and therefore without visitors. Warm spa waters irreversibly flow in streams and streets, losing huge profits that could be made by reopening this spa.

The experience of other countries, especially the Czech Republic and Slovenia, in the development of spa tourism can be used as a form of modernization of the tourist offer of spas in these areas. Namely, in recent years Slovenia has invested one billion euros in the development of this tourist branch, building 15 state-ofthe-art spa centers, so that in the total income from tourism in this country, spa tourism participates with about $50 \%$. This type of tourism in Slovenia was developed thanks to investments, which came, inter alia, from European Union development funds, whose funds are intended for balanced regional development. Experts estimate that the construction of modern spa and wellness centers, the countries of this part of the Western Balkans, could increase tourism revenue by up to $200 \%$. The area of the Western Balkans is extremely rich in cultural and historical monuments. Due to the exceptional cultural and historical treasure that is located in these areas, UNESCO has included a large number of cultural monuments in the area on the World Heritage List.

The UNESCO list includes the Albanian archeological site Butrint, which was inhabited in prehistoric times and Berat and Gjirokastra as a typical example of Ottoman architecture. A characteristic of Berat and Gjirokastra is the mixture of Christian and Ottoman culture with numerous churches and mosques. In addition to these Albanian sites, UNESCO also added to the list the old bridge in Mostar, which was demolished during the civil war in Bosnia and Herzegovina. described by Nobel laureate Ivo Andric in his piece "On the Drina River". Also, under the protection of this international organization is the "Ohrid Region". In this locality there is, among other things, the oldest monastery in this area of Sv. Panteleimon and a collection of 800 Byzantinestyle icons dating from the XI-XIV centuries, considered to be the second collection of icons in importance in the world. However, the largest number of UNESCO protected assets is in Serbia. Among them is the Old Ras complex, which, in addition to the medieval capital of Stefan Nemanja, includes the Orthodox monasteries of Sopocana, Djurdjev Stupova and the church of Sv. Peter and Paul are known as Peter's Church, located near 
the old town of Ras. In addition to this site, the monasteries of Studenica, Pec Patriarchate, Visani Decani, Bogorodica Ljeviška, Gracanica and the archeological site Gamzigrad near Zajecar are protected, which also includes an imperial palace from the Roman Empire period known as the Romuliana. These UNESCO-listed sites are a real attraction for visitors, because tourists cannot remain indifferent to their beauty.

In addition to this extraordinary tourist potential, these areas are also characterized by a large number of wellpreserved cities from prehistory, antiquity and the Middle Ages, which testify to the early existence of civilization in this region. Special tourist attractions in these areas are the earliest civilizations Lepenski Vir and Vinča, which is the seat of the so-called. The Vincentian cultures, followed by Gamzigrad and Romuliana from antiquity and, as the best-preserved, medieval cities in which there are many in this region.

Throughout the centuries, the cultures of the Balkan Peninsula have been intertwined with various cultures that have left an indelible mark and that have shaped the present-day culture of the Balkan peoples. There are a large number of churches, cathedrals, mosques and synagogues in this area that dominate these areas with their beauty and grace. These religious sites and the various "miracles" that are happening in this part of the Western Balkans are a credit for the well-developed religious tourism in this region. As a typical example of wellorganized religious tourism, we can mention Medjugorje in Bosnia and Herzegovina where pilgrims gather to see the Virgin Mary who occasionally appears to them here. Visits to Medjugorje by many tourists cannot be compared with any tourist site in Bosnia and Herzegovina. More than half of the visitors who visit Bosnia and Herzegovina annually are pilgrims from Medjugorje. In addition to Medjugorje, the capital of Bosnia and Herzegovina, Sarajevo, is the main destination for tourists in the field of religious tourism in these areas. Namely, Sarajevo is the only European city in which a small place of worship of four great faiths is situated in a small area not more than 100 meters high: the Orthodox Church, the Catholic Cathedral, the Islamic Mosque and the Jewish Synagogue. The National Museum in Sarajevo also houses his most valuable exhibit, the traditional Jewish book of the Haggadah, which the Sephardim brought to Sarajevo after his expulsion from Spain. (Neskovic, 2019, p. 31)

Religious tourism in Serbia is reflected in visits to numerous monasteries and churches, most of which date back to the Middle Ages and the golden period of the Serbian state. These graceful Orthodox monasteries, in addition to artistic and religious beauty, also represent the power of the Serbian medieval state. Most of these monasteries are colorful in the style of the Orthodox faith, and the murals on their walls represent an invaluable artistic asset. The most famous fresco of Serbian monasteries is every White Angel from the UNESCOprotected Mileševo Monastery. Also, they represent great tourist potential in the groups of monasteries in Fruska Gora and the Ovcar-Kablar Gorge. Most Orthodox monasteries in Serbia are protected by the state because of their artistic, historical and religious values, while some of them are protected by UNESCO. The Serbian monasteries of Žiča, Studenica, Gradac, Đurđevi Stupovi and Sopocani were included in the program "The main cultural path of the Council of Europe", which under the name "Transromantics" brings together and promotes the European heritage of the Romanesque period. The place of pilgrimage with the largest number of Orthodox believers in this region is St. The Virgin Mary in Junis, where thousands of Orthodox believers gather around the world every October. Also worth mentioning is the Miroslav Gospel, which dates from the 12th century and is kept in the National Museum in Belgrade. In 2005, UNESCO listed it as the "Memory of the World" library among the 120 most valuable assets created by human civilization.

A special tourist attraction of this part of the Western Balkans can be represented by religious customs that are rooted in paganism and, in addition to sacrifice on the Albanian Mount Tomori, represent a unique offering in Europe. Most of these pagan customs can be found in eastern Serbia, inhabited by Vlachs. These customs are especially pronounced in the Homolj mountains where, due to isolation from the rest of Serbia, the Vlachs kept their customs in their original form. Due to its blend of culture, pleasant climate and clean nature, the areas of this part of the Western Balkans are known worldwide for their delicious food and good quality wines. These national cuisines represent the pride of the people of this part of the Western Balkans, and to promote tourism, numerous wine routes have been traced that connect the wine centers in this region.

One of the great advantages for the development of tourism in these areas is the initial space of over 17 million inhabitants, who are forced, due to the poor economic situation in these countries, to satisfy their tourism needs in the domestic areas. However, regional co-operation is a basic prerequisite for the development of regional tourism in this region. In this regard, countries in this part of the Balkan Peninsula have started to cooperate through CEFTA, IPA Adriatica, by establishing a Western Balkans Tourism Association, which aims to attract tourists from the far east, the World Wide Fund for Nature (WWF) project to create a network park of the Dinaric Arc, but also through the special connections Serbia has with Bosnia and Herzegovina. The opening 
of mountain hiking trails in the Prokletije crossing Albania, Montenegro and Serbia in Kosovo and Metohija, for which special border crossings have been opened, can be cited as a positive step towards establishing interstate cooperation between the countries of the Balkan Peninsula. Interstate cooperation in these areas is crucial for the development of tourism as an industry branch, because this area is crossed by national borders, which causes a great migration of population towards the interior of these countries. Improving regional cooperation in the field of tourism would open many potential tourist destinations such as the Drina or Skadar Lake. (Neskovic, 2013, p. 39)

In addition to the great tourism potential that these Balkan countries undoubtedly possess, there are several deterrents to why tourism has not been sufficiently developed in these areas. The unstable political situation is the biggest problem for tourism development in this region. Due to the ethnic and religious intolerance of the Balkan peoples and the frequent ethnically-motivated war conflicts, the necessary interstate cooperation is difficult. With the lack of this cooperation, tourism in this region suffers a great deal of damage. For these reasons, there is a great aversion of the population of the developed part of Europe and the world towards the Balkans. In addition to this fundamental problem, inadequate infrastructure, which is underdeveloped due to the difficult economic situation in this part of the Balkan Peninsula, is a major drawback. The economic crisis, which has been going on in this region for too long, is the cause of the poor payment capacity of the local population. Although this area has over 17 million inhabitants, a good portion of these citizens is unable to afford tourist trips. Also, a major problem for tourism development is the lack of skilled and educated tourism staff and the sudden aging of the population in these areas. A large number of educated and able-bodied populations of these countries migrate to the developed countries of Europe and the world. Added to this is the poor legislation of these countries in the field of tourism and the inconsistency of the legislation with the regulation of the European Union. In recent years, there has been a shift in this field as countries in this part of the Western Balkans are striving to join the European Union, and are thus obliged to adapt their legislation to the laws applicable in the territory of the European Union. Although tourism is a very important industry and generates large revenues for the countries in which it is developed, there is still no need for the interest of the top states to invest in this promising branch.

\section{Conclusions}

The fact is that the Western Balkan countries have enormous potential for tourism development. Practically, no area in this region does not have the best predisposition for tourism development. A large initiative space with dynamic relief and an extremely rich cultural and historical heritage, it simply cannot, without being noticed, on the tourist map of the world. However, the fact is that tourism in this region is not developed to the extent that it belongs to its potential. The reason for this lies in society, and not in nature. Nature has given these premises all the necessary conditions, but society does not know it or will not take advantage of it.

The three main reasons why tourism, regionally speaking, is underutilized are the unstable political situation, inadequate infrastructure and the lack of interest of the authorities of these countries in the development of tourism, which includes lack of incentive measures and poor regulation. Namely, in the treated countries of the Balkan Peninsula except for Albania, there is a negative natural increase, which implies constant aging of the population. This problem is particularly pronounced in the rural areas of this region, where there is a large population migration towards urban and developed parts of these countries and developed countries of Europe and the world. Rural areas are known to represent areas where tourism should develop. Also, according to the World Tourism Organization, rural tourism will represent one of the basic types of tourism shortly. In rural areas, only old and under-educated residents remain who cannot in any way contribute to tourism development. Also, these spaces do not have developed infrastructure. Most rural areas lack electricity and roads, while we cannot even talk about phones and the Internet. Without the development of infrastructure, we cannot talk about the development of tourism in this region.

The solution to this problem could be found by implementing strategies in these areas and implementing incentive measures, among other things, in the form of favorable tax policy and priority employment of the local population in the field of tourism. The same is the case with border areas, which are most often ideal for tourism development. Due to the proximity of the border, but also the underdevelopment of these areas, young and educated residents of these areas migrate inland to their home countries. The solution for the development of tourism in the border areas could be found through interstate agreements and programs for the development of tourism, such as the example of cooperation between Montenegro, Albania and Kosovo in the Prokletije. Successful tourism development requires trained staff in this field. The implementation of incentive measures should help the return of young and educated people to the rural areas of this part of the Western Balkans. By 
ISSN 2661-2666 (Online) International Scientific Journal Monte (ISJM) DOI:10.33807/monte.202004673 Volume 3 No. 1 (2020): April

building infrastructure in the rural parts of this region and educating staff in the field of tourism, the basic prerequisites for accelerated development of the beautiful and unused areas of the Balkan Peninsula would be gained.

Also, these areas represent great potential for the development of sports tourism, and thanks to a large number of spas that are mostly located in passive areas, and for the development of health tourism, which, in addition to rural, represent the future of tourism in these areas. The accession of these countries to the European Union would open up the possibility of access to various funds for a balanced regional development of the European Union. Therefore, underdeveloped Balkan countries such as Serbia, Bosnia and Herzegovina, Albania and Macedonia could, with the assistance of the European Union, be able to invest more seriously in the development of this very important industry.

The importance of tourism in building an economically strong state can best be seen in the example of Greece, which, despite the great economic crisis it is in, successfully resists thanks to developed tourism. This industry has been one of the few in recent years to record a positive trend in the shaky Greek economy. Judging by the facts, with the Western Balkans' serious tourism strategy, fresh capital injection, cross-border cooperation and smart use of natural resources, tourism in these areas could flourish in the coming years and become one of the main pillars for the development of the economies of these countries. 
ISSN 2661-2666 (Online) International Scientific Journal Monte (ISJM) DOI:10.33807/monte.202004673

Volume 3 No. 1 (2020): April

\section{References}

Neskovic, S. (2013) European Integration and Tourism Development in Southeast European Countries. International Conference Contemporary Trends in Tourism Development.

Neskovic, S. (2013) Traffic Corridors in the Function of the Progress of Southeast European Countries. International Conference on Road Mobility and Safety, Travnik International University.

Nesković, S. \& Jovanovic, Z. (2016) Ecological Paradigm Within the Context of the International Policy Development Study. Balkan Journal of Philosophy, Vol. 8.

Neskovic, S. (2013) External Security Policy of the European Union and the Position of the Republic of Serbia - Case Study. Belgrade: Center for Strategic Research on National Security - CESNA B.

Nešković, S. (2018) Geostrategic Position and Security Synergies of the Black Sea Region through Cooperation with the European Union. Cross - Border Book Series "New Challenges to Security and Development of the Balkans" Vol. 5.

Neškovic, S., Ketin, S., Secerov, P., \& Djelic, T., A. (2018) International Politics and Ecology: A Focus on Environmental Protection. Fresenius Environmental Bulletin - FEB, Vol. 27. No 11/2018.

Neskovic, S., Jokanovic, I., \& Stefanovic, G. (2018) Reconstruction of Dysfunctional Urban Corridors: Case Study Cairo. Journal of Road and Traffic Engineering Vol 64, No 4.

Neskovic, S. (2019) Business Diplomacy in New Trends in Transport, Ecology and Logistics, 19th International Conference "Innovation and Research in the Function of Technical and Technological Changes in Transport, Ecology and Logistics.

Neskovic, S., Djelic, T. A., Antonovic, R., Lutovac, M. \& Ketin, S. (2020) Incorporation of Information Communication Technologies in Economic and Environmental Espionage, Fresenius Environmental Bulletin - FEB, Volume 29 - No 05/2020.

Spasojevic, M. \& Susic, V. (2011) Contemporary Tendencies in the Development of Health Tourism in the World and Serbia. University of Niš, Faculty of Economics Niš, Niš. 


\title{
IMPACT OF EU GRANTS ON EDUCATION IN KOSOVO
}

\author{
Prof.Ass.Dr.Theranda Beqiri ${ }^{1}$ \\ Ms.sci.Arbërora Haxhija² \\ ${ }^{1}$ University Haxhi Zeka, Faculty of Business \\ Theranda.Beqiri@unhz.eu \\ ${ }^{2}$ Agency for Western Regional Development \\ Arbërora.Haxhija@ardawest.eu
}

\begin{abstract}
The main purpose of this paper is to present the investments made so far and the impact of these investments on the development of human capacities. This paper will also identify the potentials and needs for further development of human resources in both formal education and vocational training. It is important that the population of Kosovo is well prepared for Kosovo's integration into the European Union so that future investments are oriented towards sustainable development through long-term investment policies and strategies. Although there are some reforms in Higher education still many reforms are needed to be implemented also in primary and secondary education. There is a need for skills that match the labor market needs and creation and development of these skills depends mainly on the quality of the education system, its relationship with the labor market, the conditions in which people work in the labor market, but also the opportunities to gain skills through vocational trainings or further educations.. Vocational training is very low, while at least a quarter of vocational schools do not offer internships in or out of school. Enterprises have no incentives to hire interns and in educational institutions there are limited career guidance although we found that grants have had their impact in higher education in improving the policies and curriculum development in each level of educations and through different trainings of teachers in primary and secondary schools. We find that although there is a high level of grants in education sector, a lot of resources are still needed to enhance the education quality in all levels, there is a need of infrastructure and increased improvement in curricula that than impacts in the increased quality of education.
\end{abstract}

Key words: Grants, Education, Curricula, Strategy, Training, EU,

\section{Introduction}

Kosovo is one of the countries that during the post-war period have witnessed many phenomena that society had to build up as a consequence of the conflict. Being among the youngest countries in the world, Kosovo faces many challenges and difficulties to become a member with equal rights in the large family of the European Union. The gradual weakening of the industry, the constant obstacles to sustainable development and, more importantly, the difficulty of maintaining the teaching process have influenced Kosovo as a society to lag behind the countries of the region. In this context, the international community in order to support the recovery of state has decided various bodies to operate in Kosovo aiming at supporting the sustainable economic development. Since 1999, the United Nations Interim Administration Mission (UNMIK) has been leading the state of Kosovo by governing municipalities and managing Kosovo's state assets. During this period, almost all socially-owned enterprises in Kosovo have been privatized, replacing almost the entire existing industry with private ownership. At the same time, many other donors have invested through donations in the recovery of our state. Different donors such as USAID, KFW, GIZ, Swiss Contact, SIDA through their programs have supported different programs and sectors. Undoubtedly, the European Union is one of the supporters of Kosovo through grants and technical assistance in Kosovo. The EU is present in Kosovo through the Special Representative in Kosovo. The EU Office in Kosovo has played a key role in international efforts to build a new future for Kosovo since 1999.Kosovo has received more than $€ 2.3$ billion since 1999 and nearly $€ 1$ billion to support Kosovo's international presence in the European Union alone. Given the full support provided by the EU as well as other implementing donors of investment programs of various governments, we need to think about the outcome of these investments and look closely at the impact of these funds on the development of human resources. The mismatch of labor market needs 
with the knowledge gained in higher and vocational education has been identified as one of the main obstacles to employment growth and economic development in the country. About $25 \%$ of firms in Kosovo still complain that the workforce has incomplete and incompatible skills. On the other hand, more than $85 \%$ of investors underline the quality of the workforce as the main factor when making investment decisions. The education sector is still affected by the lack of adequate facilities, maintenance and quality assurance. Crucial challenges to be tackled in the education sector include improving the quality of primary and secondary education, vocational education and training; strengthening transparency in the education system; investment in teacher skills. When we talk about skills, we are not only talking about technical skills, such as cutting and shaping a product, but also about cognitive skills, such as logic and reasoning, or soft skills such as relationships with colleagues or work ethic. The creation of these skills depends mainly on the quality of the education system, its relationship with the labor market, the conditions in which people work in the labor market, but also the opportunities to gain skills through vocational trainings or further educations.

\section{Insights from Kosovo Region}

The Republic of Kosovo is at an important stage when the development agenda should be oriented towards European integration in all areas. Such a European development orientation comes naturally after overcoming the emergency and stabilization phase during 1999-2007, and the state-building phase in the period after the declaration of independence. During the emergency and stabilization phase, we as a society together with our international partners focused on rebuilding the destroyed basic infrastructure as well as creating normal living conditions. Then, in the construction state phase, our energies were oriented towards the construction of the institutional architecture of the state as well as the elementary physical infrastructure for development and wellbeing. Thus, public investments were oriented towards the creation of new state institutions, the development of educational and health infrastructure, as well as other infrastructure necessary for sustainable development. While economic growth rates have been modest in recent years, including the global economic crisis - an average of $3.3 \%$ a year since 2009 - and have had an effect on reducing overall poverty levels, they are likely to be even higher. In fact, they need to be higher to enable Kosovo to develop sustainably and meet higher living standards. Per capita income in Kosovo is at the level of $11 \%$ compared to European Union countries and to achieve this level of the EU. The Table 1 below shows the comparison of five selected indicators Kosovo needs a growth rate of about $8 \%$ for the next 30 years. Also, given that Kosovo stands behind the average of Southeast European countries that are not members of the EU based on a number of key economic and social indicators, which speak to the level of economy and quality of life, initially the goal ours is to achieve the level of these places (illustrated in the table below).

Table 1. Comparison of five selected indicators

\begin{tabular}{|l|l|l}
\hline Indicator & Kosova & $\begin{array}{l}\text { Average of Southeast European countries } \\
\text { that are not members od EU }\end{array}$ \\
\hline Gross local product per capita & $€ 2.935$ & $€ 3.504$ \\
\hline Unemployment rate & $30,1 \%$ & $20,8 \%$ \\
\hline Participation in the labor market & $40,5 \%$ & $49,7 \%$ \\
\hline Percentage of the population living in poverty & $29,9 \%$ & $19,7 \%$ \\
\hline The ratio between exports and imports & $12 \%$ & $46.5 \%$ \\
\hline
\end{tabular}

Source; Indicative strategy paper for Kosovo

\section{Materials and Methods}

Based on economic theory human capital offers an alternative logic to understand the choices that firms make in human resource management. The essence of this theory is that people are valuable to the organization to the 
extent that they make it productive. Thus, organizations need to make decisions about investing in people just as they make decisions about investing in machinery; they need to treat their employees as a form of their capital. Expenditures related to training, retraining, motivation and monitoring of the organization are seen as investments in the human capital of the firm as well as the maintenance of machinery would constitute an investment in the firm's capital. Human capital theory can be used to gain knowledge in decisions where firms organize or reorganize for their staff and their human capital operations. A standard approach from the point of view of the labor economy, human capital is presented by the characteristics as well as the skills that increase the productivity of employees. This can generally be taken as a general definition, but there are many studies that have contributed and provided some alternative and complementary thoughts on human capital. According to (Becker, 1964), human capital is directly needed in the production process, more explicitly human capital increases the productivity of employees in all tasks, but normally differently in different tasks and different organizations, e. which although generalized makes sense since the level of knowledge and ability of employees is directly related to the function of productivity. When it comes to grants in education according to Carneiro et al (2020) sometimes government and authorities does not know the needs of the schools and universities and therefore we do not see improvement in their general scores .whilst when comes to the labor market to select and retain a satisfying employee there are some issues that needs to be developed as training and development and interaction of organizations strategy with human resources development, in order to reach competitive advantage in the field that they are working Holland et al (2007). Sun, M., Penner, E. K., \& Loeb, S. (2017). Whilst Sun \& Loeb (2017) in their research analyzing grants for low performance schools found that the improvements in the success of schools takes long time and improvements in the performance of the schools can be seen only in the third year of grants. Bing, Kehrhahn \& Short, (2003) say that human resources development should be integral part of the organizations taking into account short and long planning which is than correlated with the increased wellbeing of the society rather than just as an internal issue of the organization. Okoye \& Ezejiofor (2013) exploring the effect of human resources development on organizational productivity.

\section{Methods of research}

The main purpose of this paper is to present the investments made so far and the impact of these investments on the development of human capacity. Also, through this work, the potentials and at the same time the needs for further development of human resources will be identified, both by professional and technical trainings. It is important for Kosovo's integration into the European Union so that future investments can be oriented towards sustainable development through long-term investment policies and strategies. The methods that are used is mainly through secondary data through analyzing of investments and grants in Kosovo from the EU donors through different reports, also it is analyzed the impact of these investments on human resources and the impact on sustainable economic development taking into account the human factor, drawing conclusions and recommendations for planning and orienting investment funds regarding the development of human resources. We use the data from the time period of 2008 until 2015 and do some comparisons and analysis, as well as further donations and strategies in recent years.

The research questions are:

1. What strategies and plans have been used by the institutions and what are the processes and activities should be undertaken in order to successfully implement these strategies?

2. How will the impact of these undertaken activities be assessed and measured?

3. What are the benefits to society of achieving these specific objectives?

\section{Results}

\section{EU Investments in the Education Sector in Kosovo 2008-2015}

This part of the paper presents the plans and policies of the central institutions and line ministries regarding the activities and measures for the development of human resources as well as the main donor for Kosovo, the European Union. As we have seen in the indicative plans the development of human resources and employment is one of the five areas of action foreseen with the strategic document for Kosovo from IPA II funds, a total of 645 million euros. This part of the paper also reflects the investments made in this sector by the European Union. 
The data are taken from the annual reports of the Ministry of European Integration for sector and donor. As can be seen from the graphs below presented for this reporting period, the EU is the donor who leads the investments made for the period 2008 - 2015. Sector Education and employment is composed of six sub-sectors: employment, welfare and inclusiveness, higher education, research and innovation, pre-university education, vocational training and education (teaching for adults and throughout life), youth and other employment and education. Including cultural, recreational and heritage activities. Based on this report, from 2008 to 2015, donors spent approximately 215.6 million euros.

Fig.1 Presentation of planned and current distribution (2008-2015) in the education and employment sector

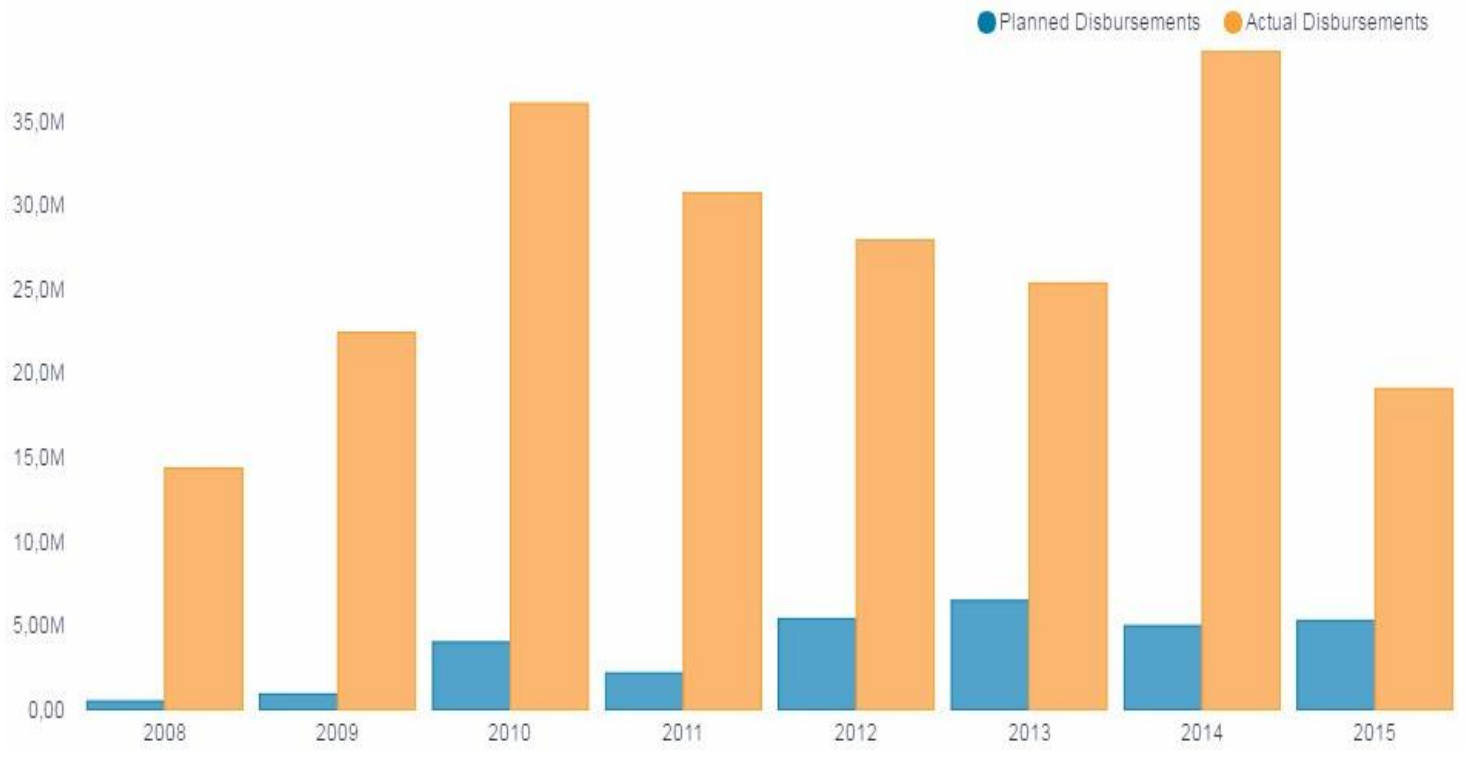

Source; Ministry of European Integration Annual Report Donor Profiles, MEI, 2016

According to the report for Kosovo Indicative Strategy, (IPA II) Kosovo does not have a comprehensive development strategy. However, a large number of medium-term strategies exist. According to the Indicative Strategy Paper for Kosovo, IPA II, steps have been taken in this direction in recent years, but a long-term strategy for Kosovo is lacking. In general terms, even sector planning is at an early stage. Although, comprehensive and realistic strategies have been developed in some sectors by the relevant ministries, often these strategies have been designed with the help /and assistance of various donors among which is also the Strategic Plan for Education in Kosovo 2011-2016. The Employment and Welfare Strategy 2014-2020 is a comprehensive strategy aimed at improving the functioning of the labor market, promoting the development of skills, covering the welfare system and consolidating the role of social partners. From the data below table 3 we can see the level of donors in education and employment sector while in many currencies (million euros) we can see the levels of donations of EU compared with other donators. 
ISSN 2661-2666 (Online) International Social Science Journal Monte DOI: 10.33807/monte.202004675 Volume 3 No. 1 (2020): April

Table 3 .Percentage of donors in the Employment and Education sector 2008-2015,

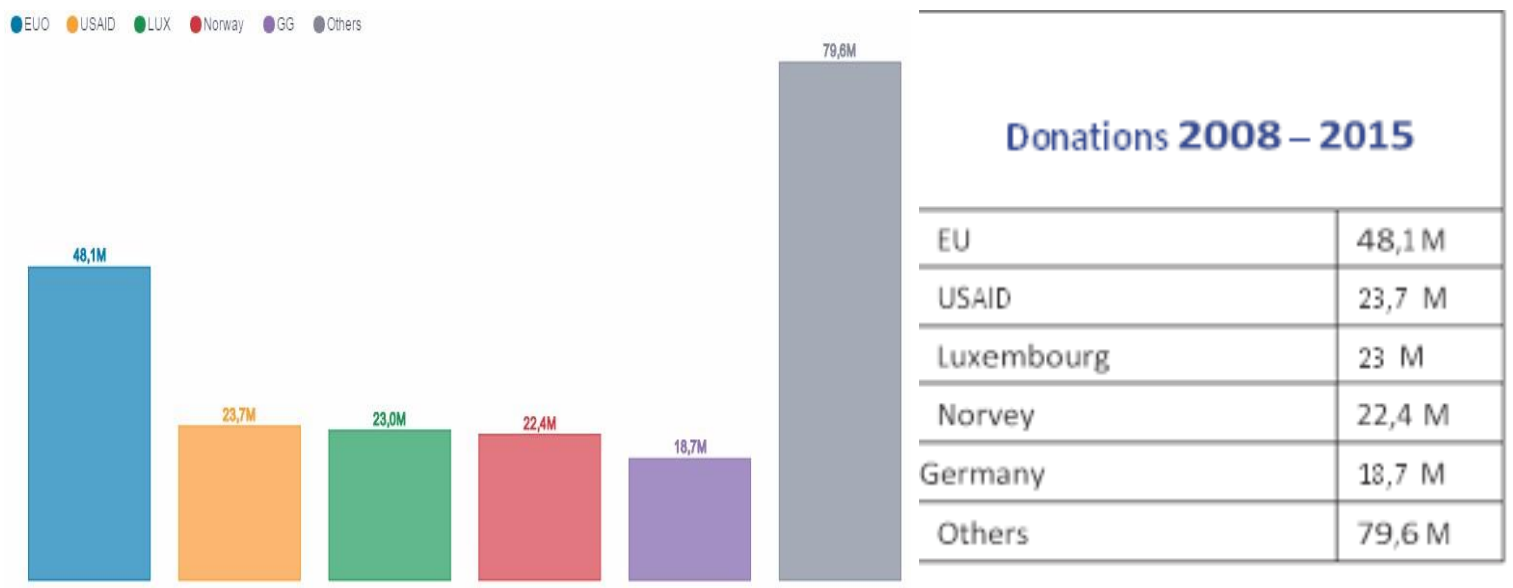

Source; Annual Report Donor Profiles, MEI, 2016

\section{Discussions}

If we consider some indicative targets from the strategy paper (2014-2020) some of the main challenges for Kosovo are; increase of enrolment of pupil's students in all levels of education, improving infrastructure, increasing the quality of education, increasing participation of students in vocational education and matching the skills with needs of the labor market. If consider the public spending around $4 \%$ of the GDP is spent in education sector. Furthermore, according to strategy paper pg44 (2014-2020) " $75 \%$ of overall spending on education is for salaries and increases in education spending are used almost entirely for salary increases rather than education quality improvement (only $0.2 \%$ of education spending was allocated for training of teachers)". Although the strategic plan 2016-2021 says that the focus shall be oriented in training of teaching staff and to ensure a professional development of teachers should be based on unified standards. Although there are teacher trainings especially staff in primary and secondary education, the trained teachers teach with old text books. If we consider the curriculum development in 2011, MEST produced a new Kosovo Curriculum Framework (CCF) with the aim of increasing the quality of education and harmonization of education with developed countries. Analysis of Kosovo's Education System, (2020) This new curriculum framework ensured the transition from teaching based objectives and content to performance-based teaching and student. Human resources are the active agents who accumulate wealth, exploit material resources, build socio-economic and political organization and carry out national development. Highly skilled human resources are a pre-requisite for overall economic and national development. For many researchers, human resources are the greatest asset of an organization or company, and the knowledge gained from work experience called "unwritten knowledge" is also an added value for any conscious employer. (Millmore, 2007). While continuous investment in the advancement of knowledge and skills of human resources creates a competitive advantage for the organization or company (Mathis \& Jackson, 2011). For Kosovo according to the study conducted from Beqiri \& Mazreku (2020) the most commonly used trainings for workers in Kosovo are on job and seminar trainings, and although traditional organizational training and development programs are still useful, the new forms of development, such as rotations and coaching, start to play their role in self-directed and self-designed careers. Zaleska \& Meneze (2007). Human resources development practices and their association with employee attitudes: Between traditional and new careers. Despite the relatively large number of vocational schools and teaching fields that they provide, MEST in the Strategic Plan of Education in Kosovo (PSAK) 2011-2016 identifies a range of challenges in this sector, such as inadequate budget, insufficient learning spaces in a single shift, improving the professional capacity of human resources for system management and in teaching, improving the quality and relevance of curricula with market demands, adequate development of the qualification framework in accordance with the European one, as well as, among other things, establishing better links with enterprises for practical work goals. Consequently, the same document from MEST identifies priority for this education sector to address existing challenges and sets clear goals which through programs and activities must be achieved long planned period. The main challenges in the education sector are the improvement of quality in primary and secondary education, vocational education and training; strengthening transparency in the education sector; investments in teaching skills Higher education in Kosovo is a matter of 
linear reform with the Bologna system, but many reforms still need to be implemented. Participating in the Erasmus + program and its external dimension by supporting the modernization of higher education is in first steps in increasing the quality of higher education. Carneiro et al (2020) found that impact of grants in education in quality and learning has its impact when its combined with government and heads of school's involvement 'especially on girls and students with high ability levels at baseline, at a cost effectiveness rate commensurate with other interventions that aim to improve education outcomes in low-income countries'. In Kosovo population is the youngest in Europe and unemployment levels are approximately as high as 35 percent. Of the many unemployed, $60 \%$ of them do not have basic skills for labor market. However, the number of unemployed people with university education has increased, thus signaling a discrepancy between the skills needed for the labor market and those provided by the education system. Increasing the level and relevance of the skills of the workforce is one of the main challenges

\section{Conclusions}

Kosovo today is not in a good position in comparison with the region in terms of workers skills. At a time when unemployment in the country is very high, the paradox is that many enterprises have trouble finding skilled workers. One of the main reasons lies in the education system, namely the low involvement of the pupils in the secondary schools and the quality of teaching. Another problem is the lack of compliance of skills and abilities acquired with the demands of the labor market, as there is a lack of connections and collaboration in the triangle between schools, businesses and communities. There is no system in Kosovo for forecasting the skills required in the labor market. The process of drafting professional qualification standards is slow, as is the implementation of the Curriculum Framework. The level of public spending on education and vocational training is very low, while at least a quarter of vocational schools do not offer internships in or out of school. Enterprises have no incentives to hire interns. Schools offer limited career guidance nor enterprise connectivity opportunities through product research and development. However, even in the case of these areas, Kosovo would benefit greatly from the establishment of one or more Competence Centers, where the knowledge and skills acquired in these institutions would be complemented by special training programs. Also, creating partnerships with the private sector to establish training centers that offer international certification programs in hotel and tourism, financial and business services, and foreign languages would improve the region's competitiveness to attract investment, and would create greater employment and self-employment opportunities for the region's population. o strengthens the link between educational programs and labor market needs through the definition of professional standards and priority areas, as well as the implementation of core curricula and teacher training. The vocational education system will become as practical as possible, including internships at the enterprises. 
ISSN 2661-2666 (Online) International Social Science Journal Monte DOI: 10.33807/monte.202004675 Volume 3 No. 1 (2020): April

\section{References}

Becker, G. (1964). human capital, NY. GS Becker.

Beqiri, T., \& Mazreku, I. (2020). Lifelong Learning, Training and Development Employee's Perspective. Journal of Educational and Social Research, 10(2), 94-94.

Bing, J. W., Kehrhahn, M., \& Short, D. C. (2003). Challenges to the field of human resources development. Advances in Developing Human Resources, 5(3), 342-351.

Carneiro, P., Koussihouèdé, O., Lahire, N., Meghir, C., \& Mommaerts, C. (2020). School Grants and Education Quality: Experimental Evidence from Senegal. Economica, 87(345), 28-51.

Holland, P., Sheehan, C., \& De Cieri, H. (2007). Attracting and retaining talent: Exploring human resources development trends in Australia. Human Resource Development International, 10(3), 247-262.

Mathis, R. L., \& Jackson, J. H. (2011). Human resource management: Essential perspectives. Cengage Learning.

Millmore, M., \& Lewis, P. (2007). Strategic human resource management: contemporary issues. Pearson Education.

Okoye, P. V. C., \& Ezejiofor, R. A. (2013). The effect of human resources development on organizational productivity. International Journal of Academic Research in Business and Social Sciences, 3(10), 250 .

Perlman, C. L., \& Redding, S. (2011). Handbook on Effective Implementation of School Improvement Grants. Academic Development Institute.

Sun, M., Penner, E. K., \& Loeb, S. (2017). Resource-and approach-driven multidimensional change: Three-year effects of School Improvement Grants. American Educational Research Journal, 54(4), 607-643.

Zaleska, K. J., \& de Menezes, L. M. (2007). Human resources development practices and their association with employee attitudes: Between traditional and new careers. Human relations, 60(7), 987-1018.

Analysis of Kosovo's Education System,(2020) Aliu Luljeta 2020 Friedrich Ebert Foundation retrieved from URL http://library.fes.de/pdf-files/bueros/kosovo/15185-20190220.pdf Accessed $21^{\text {st }}$ of march 2020

Indicative Strategy Paper for Kosovo (2014-2020) retrieved from URL https://eeas.europa.eu/headquarters/headQuarters-homepage/50070/indicative-strategy-paper-kosovo2014-2020_ku accesed 7th april 2020

Indicative Strategy Paper for Kosovo, retrieved from URL https://ec.europa.eu/neighbourhoodenlargement/sites/near/files/20180817-revised-indicative-strategy-paper-2014-2020-for-kosovo.pdf

MIE, 2015 sector screening report, retrieved from URL https://www.mei-

ks.net/repository/docs/anualreportsectorscreening.pdf aaccessed20th of January 2020

MIE, 2016 Annual report Donor profile MIE, retrieved from URL https://www.meiks.net/repository/docs/anualreport_english_3.pdf accesed 5th ofnovember 2019

Strategjia Kombetare per Zhvillim 2016-2021 ( SKZH) retrieved from URL http://www.kryeministriks.net/repository/docs/Strategjia_Kombetare_per_Zhvillim_2016-2021_Shqip.pdf accessed 5th of march 2020 